\title{
Sandstone Ground Stone Technology: a Multi-level Use Wear and Residue Approach to Investigate the Function of Pounding and Grinding Tools
}

\author{
E. Cristiani ${ }^{1}$ (I) $\cdot$ A. Zupancich ${ }^{1}$
}

Accepted: 27 September 2020/ Published online: 13 October 2020

(C) The Author(s) 2020

\begin{abstract}
Ground stone tool (GST) technology includes artefacts utilized in pounding or grinding activities and characterized by long life cycles and multiple uses. The introduction of such technology dates back to early prehistory, and for this reason, it is used as prime evidence for tackling a wide range of archaeological questions such as the origins of technology, patterns of daily subsistence and lifeways. In this paper, we contribute to the field of study of GSTs by discussing the application of a novel multi-level analytical approach combining use wear and residue observations at low and high magnification with residue spatial distribution investigated using GIS. We aim to assess the potential of a combined use wear and residue approach to (1) discriminate specific gestures and worked materials on sandstone GSTs and (2) understand the potential of residue distributions for reconstructing ancient GST functions and, more specifically, the role of GSTs recovered at Mesolithic sites of the Danube Gorges region in the Central Balkans. We identified diagnostic surface modifications associated with the use of GSTs in different activities involving both animal and plant materials. Morphological characteristics of residues have been described under reflected and transmitted light and characterized using biochemical staining. Finally, we mapped residues across the utilized surfaces of experimental tools to link patterns of residue spatial distribution to specific materials and gestures. We expect our methodological approach will be taken up by other researchers in order to produce comparable datasets on GSTs and improve our understanding of their ancient functional biographies.
\end{abstract}

Keywords Ground stone tools · Use wear analysis · Residue morphological analysis · Biochemical staining · GIS · Experiments

Electronic supplementary material The online version of this article (https://doi.org/10.1007/s10816-02009488-1) contains supplementary material, which is available to authorized users.

E. Cristiani

emanuela.cristiani@uniroma1.it

Extended author information available on the last page of the article 


\section{Introduction}

Ground stone tools (henceforth GSTs) are non-flint tools used in grinding, pounding, abrading, pecking and polishing of vegetal, animal and mineral materials (Adams 2014; de Beaune 2004; Dubreuil et al. 2015; Dubreuil and Savage 2014), generally characterized by long functional histories (Dubreuil et al. 2015; Dubreuil and Savage 2014). While exceptions to this pattern exist (Caricola et al. 2018), the functional complexity of GSTs has made them particularly suitable for tackling a wide range of archaeological questions. Scholars have studied the earliest pounding technology to understand the origins of human cognition and more complex knapping techniques (Arroyo et al. 2016, 2020; Arroyo and de la Torre 2020; Bril et al. 2012; Carvalho et al. 2019; Haslam et al. 2009, 2013; Proffitt et al. 2018). Questions about paleo diet and the role of carbohydrate-rich foods in ancient foragers' subsistence have been investigated through the analysis of GSTs in the Near East (Dietrich et al. 2019; Dietrich and Haibt 2020; Dubreuil and Nadel 2015; Piperno et al. 2004), Europe (Aranguren et al. 2007; Lippi et al. 2015; Revedin et al. 2010), China (Li et al. 2019, 2020; Liu et al. 2017) and Africa (Barton et al. 2018; Lucarini et al. 2016; Lucarini and Radini 2019). Such familiarity with plant foods and GST technology also extends to the oldest archaeological inoccupation of Australia (Fullagar et al. 2015, 2017; Hayes et al. 2018; Pardoe et al. 2019). Dynamics related to the intensification of plant processing during the period pre-dating the emergence of the first agricultural societies in the Levant have also been demonstrated analysing the use of GSTs (Dubreuil and Nadel 2015), together with their involvement in ritual activities (Dubreuil et al. 2019). Last, socio-cultural changes associated with the introduction of agriculture and craftsmanship as well as social organization of labour and the emergence of socio-economic inequality have recently been explored through the study of GST functional biographies (Adams 2014; Belfer-Cohen and Hovers 2005; Dietrich et al. 2019; Dubreuil et al. 2015; Dubreuil and Plisson 2010; Hamon 2008; Rosenberg 2008; Stroulia 2003; Wright 2014).

In the last decade, research on GSTs experienced exponential growth with the development and application of novel methodological frameworks. A large variety of qualitative and quantitative techniques, including use wear analysis, mechanical tests, 3D modelling, surface morphometrics, spatial and residue analyses and experimental frameworks have been proposed (Arroyo and de la Torre 2020; Benito-Calvo et al. 2015, 2018; Caricola et al. 2018; Caruana et al. 2014; Delgado-Raack et al. 2009; Hayes et al. 2017; Hayes and Rots 2019; Procopiou et al. 2002; Zupancich et al. 2019). However, scholars have debated the lack of a shared analytical protocol for functional analysis (Cnuts and Rots 2018; Hayes et al. 2017; Marreiros et al. 2020; Zupancich et al. 2019). In particular, arguments have been raised concerning the application of qualitative and quantitative approaches, the protocols for extracting ancient residues and the risk of modern contamination. (Cnuts and Rots 2018; Marreiros et al. 2020; Mercader et al. 2017, 2018). Moreover, patterns of residue spatial distribution have primarily been explored on knapped stone tools (Langejans 2011; Wadley and Lombard 2007; Xhauflair et al. 2017), while in the case of GSTs more effort has been put in the analysis of starch granules (Mercader et al. 2018; Zupancich et al. 2019).

Building on these premises, this paper presents the results of a combined qualitative and quantitative analysis on experimental GSTs with a twofold aim: (1) improving the methodology of functional analysis of sandstone GSTs with a particular focus on the 
identification of specific use wear and residues, and (2) reconstructing ancient functional biographies of the Mesolithic GSTs recovered in the Danube Gorges region of the Central Balkans (Antonović et al. 2006; Borić et al. 2014).

The rich GST assemblages recovered at several Mesolithic sites in the Danube Gorges (e.g., Lepenski Vir, Vlasac, Padina, Hajdučka Vodenica) mainly consist of naturally shaped sandstones pebbles (Antonović et al. 2006; Borić et al. 2014; Srejović 1969; Srejović and Babovic 2011), although boulder artworks and mortars were also recovered at Lepenski Vir (Borić et al. 2018) as well as fish stone clubs, sometimes engraved with carved linear patterns (Srejović 1969, 1972; Srejović and Babovic 2011). To date, research on the abovementioned GSTs has mainly focused on the characterization of their morpho-technological features (Antonović et al. 2006; Borić et al. 2014). However, a preliminary functional screening of GSTs from Vlasac, Padina and Hajdučka Vodenica has revealed the presence of functional modifications and well-preserved residues on their surfaces. Besides, the use of GSTs in the daily life activities was indirectly inferred from the analysis of other strands of archaeological evidence. In particular, production marks on osseous tools and manufacturing waste suggest that the chaîne opératoire of the bone, ivory and antler tools involved the use of indirect percussion and abrasion, techniques for which GSTs would have been required (Borić et al. 2014; Cristiani and Borić 2020). Abrasion was also performed to create shell ornaments and stone beads (Borić et al., 2014). Last, starch granules from processed plant foods were retrieved in the human dental calculus at the site of Vlasac (Borić et al. 2014; Cristiani et al. 2016; Cristiani et al. 2018), while nutshells, possibly processed using GSTs, were also recovered as macro-remains at the same site (Borić et al. 2014; Marinova et al. 2013).

In this work, experimental GST replicas have been used for processing animal and vegetal matters, and we provide a qualitative assessment of use wear and residues observed at low and high magnification on their surfaces. Biochemical staining has also been used for characterizing animal residues. Patterns of residues spatial distribution across the utilized surfaces were monitored using Geographic Information System (GIS) and their potential to discriminate specific gestures and worked substances discussed.

We believe that our results can provide a methodological reference for interpreting the function of archaeological sandstone GSTs by detailing specific use wear and residues patterns and monitoring their spatial distribution in relation to diverse activities and worked substances. Moreover, the information gathered through GIS has the potential to enhance sampling strategies and reduce the risk of a misinterpretation of archaeological residues caused by modern contamination.

\section{Materials and Methods}

Experimental activities were designed within the scopes of the project "HIDDEN FOODS - Plant foods in Palaeolithic and Mesolithic societies of south-eastern Europe and Italy" (ERC StG Project no. 639286). Our experimental collection is composed of 11 sandstone GST replicas made out of unmodified, naturally rounded pebbles collected from the bed of the Bojetinska River in the Danube Gorges (Central Balkans, Serbia). The raw material is macroscopically homogeneous and characterized by grains with a high degree of angularity, densely distributed within the matrix and with sizes ranging between 0.2 and $1 \mathrm{~mm}$. 
GST replicas were employed as both active (no. 5) and passive (no. 6) elements for processing plant seeds (Avena barbata and Aegilops ventricosa) and cracking nuts (Corylus avellana) as well as soft and hard animal tissues (Cervus elaphus bone, tendons and hide) both in resting (no. 6) and thrusting (no. 5) percussion, for a total of $22.75 \mathrm{~h}$ of work. Each tool or set of tools (i.e. active and passive) was used for a single activity, except for two replicas involved in two different tasks and role (exp_\#6; exp_\#8) (for details see Table 1) (Fig. 1).

Indirect evidence associated with the use of the Mesolithic GSTs in the Danube Gorges provided the background for the creation of the experimental reference collection discussed in this article. In particular, specific plant and animal materials to be processed during the experimental activities were selected on the basis of the rich archaeological evidence. Namely, wild oat grains (Avena barbata), wild grass grains (Aegilops ventricosa) and hazelnuts (Corylus avellana) were selected as particles of these plants were retrieved as starch granules in the dental calculus matrix and/or were found in the macro-botanical remains from the site of Vlasac (Cristiani et al. 2016; Marinova et al. 2013; Cristiani et al. 2018). Cervus elaphus skin and metapodials were used as red deer antler, and metapodial bones were selected as raw material for producing tools at all the Mesolithic sites of the region (Borić et al. 2014) along with the exploitation of this animal species as a food source (Boric 2001, 2002); tendons were processed as strings of sinew were used for sewing ornaments (Cristiani et al. 2014; Cristiani and Borić 2012).

Our analytical workflow (Fig. 2) included: (1) spatial distribution analysis of macroscopic residues; (2) low magnification analysis of residues; (3) residue sampling; (4) sample washing; (5) low magnification analysis of surface modifications; (6) high magnification analysis of surface modifications; and (7) analysis of residues under transmitted light.

\section{Residues Spatial Distribution Analysis}

The spatial distribution of residues adhering to the surfaces of the tools was analysed using Geographic Information System (GIS) software (Arroyo and de la Torre 2020; BenitoCalvo et al. 2015; Caricola et al. 2018; de la Torre et al. 2013; Zupancich et al. 2019). Zenithal pictures of the washed tools were taken with a Canon EOS 100D equipped with a Fixed $50 \mathrm{~mm}$ Macro Lens, imported in QGis (v.3.12) and georeferenced using a $20 \mathrm{~cm} \times$ $14 \mathrm{~cm}$ grid. For the analysis of residue spatial distribution, pictures of the washed tools were used. This choice was made to document the distribution of residues on archaeological specimens. The outline of the utilized surfaces and the residue spread across them were rendered as vector shapefiles. This allowed us to define the dimensions of the patches of residual material (area and perimeter) as well as their distance from the surface geometric centre (DC), the edges (DE) and the geometric centre of the utilized area of the surface (DUA). Such variables have already been proven useful in the analysis of the spatial distribution of use wear and starch granules on GSTs (Arroyo and de la Torre 2018, 2020; de la Torre et al. 2013; Mercader et al. 2018; Zupancich et al. 2019). Moreover, the dispersion of the residues across the surface was calculated through a standard deviational ellipse (SDE). Subsequently, these parameters were cross compared with the performed activities, the processed materials and the role (active or passive) of the tools to highlight potential spatial distribution patterns. 


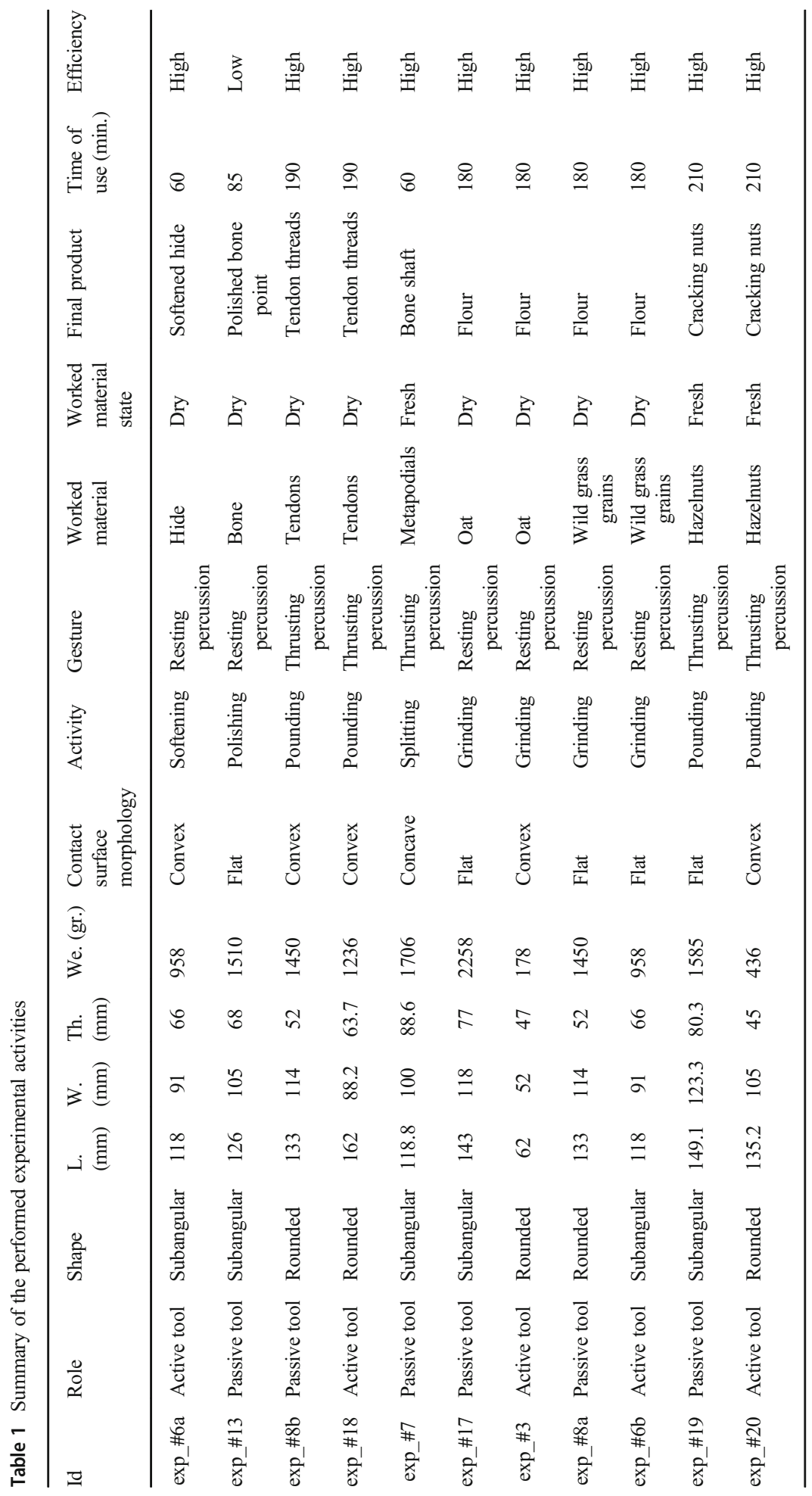




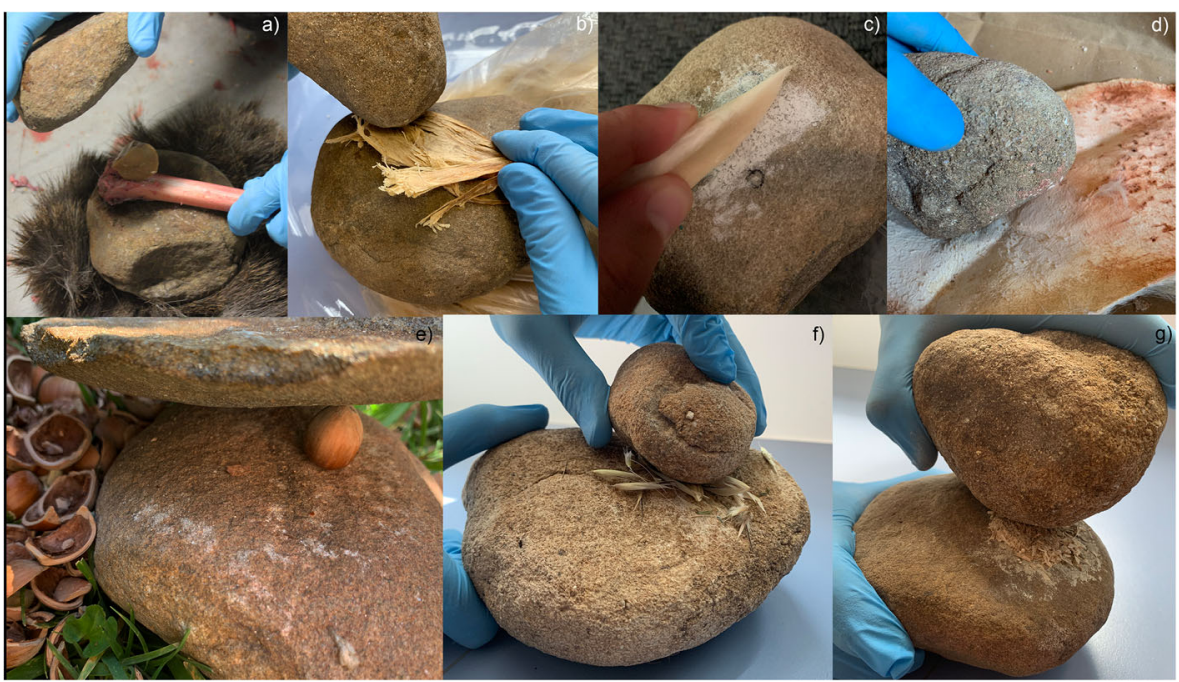

Fig. 1 The experimental activities performed using GST replicas. a Splitting fresh metapodials; b pounding dry tendons; c polishing dry bone; $\mathbf{d}$ softening dry hide; e hazelnut cracking; $\mathbf{f}$ grinding oat grains; $\mathbf{g}$ grinding wild grass grains

\section{Residue Morphology and Biochemical Staining}

First, residues were macroscopically analysed in situ using a Zeiss AxioZoom V16 Digital Stereoscope equipped with a PlanNeoFluar Z1x/0.25 FWD objective and $\times 10$ eyepiece (magnifications ranging from $\times 7$ to $\times 112$ ) and then extracted and analysed in bright field mode under transmitted light using a Zeiss Imager2 with magnification up to $\times 1000, \times 10$ eyepiece and cross-polarization.

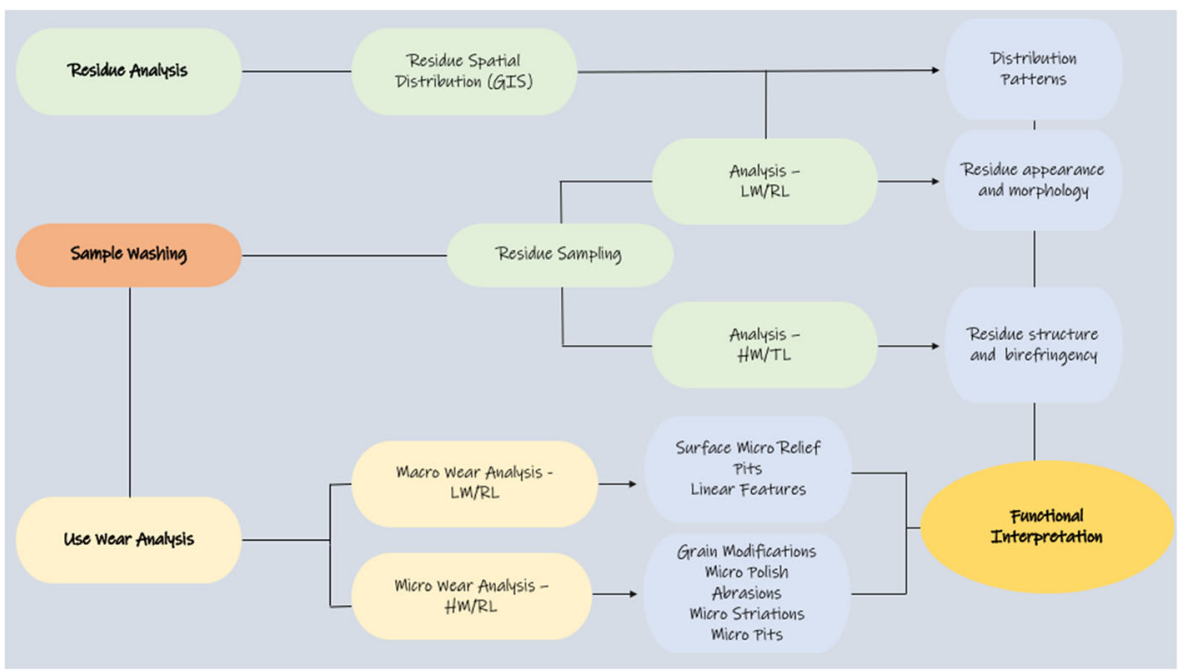

Fig. 2 Workflow of the analytical framework presented in this paper. LM, low magnification; HM, high magnification; RL, reflected light; TL, transmitted light 
At low magnification, residues were described according to their appearance, using variables such as morphology, superficial texture, colour and birefringence. Potential features connected with mechanical stresses affecting the appearance of the residues and functionally related were also recorded. Identifiable morphological features of plant and/or animal structures were recorded and described.

Following the observation at low magnification, starch granules were extracted and analysed in transmitted light following criteria widely accepted by modern and ancient starch analysts (Henry 2020; Mercader et al. 2018; Yang and Perry 2013). The sampling of the experimental tools' surface was carried out using ultrapure water, placing $20-\mu l$ droplets on spots where the residual material was visible. The drops were left 1 min on the artefact to soften the residues and then pipetted out and mounted with a $50 \%$ solution of purified water and glycerol. Experimental starch granules description was based on the geometric morphometric typology of the grains (Mercader et al. 2018), position and form of the hilum, presence and appearance of surface features, depressions, fissures, presence of lamellae and extinction cross, birefringence and specific distribution (e.g. bimodal distribution and presence/absence of lumps) (Haslam 2004; Horrocks 2005; Piperno et al. 2000). The preservation of starch granules (complete or damaged) was recorded together with their dimensions.

In the case of animal substances, residues were sampled from the sandstone surface following the same criteria used for starch granules, exception made for the use of staining. Once pipetted out, the sample was placed onto a glass slide, stained using Picrosirius Red (PSR), following the protocol established by Stephenson (2015) and then analysed in transmitted light using cross-polarization.

PSR is a biochemical stain, widely employed in medical studies due to its potential to react with type I (fibres) and type III (reticular fibres) collagen (Stephenson 2015). In particular, when in contact with animal fibres/tissues (e.g. hide, tendons and bone), PSR stains them into a vivid red and enhances their birefringence in cross-polarized light (see Stephenson (2015) p. 236 for details). Another factor leading to the choice of PSR staining is its potential to mark collagenous material in ancient residual matter characterized by altered morphological features due to intense processing (Stephenson 2015). Moreover, in our own experience, PSR has a lower chance of false positive than other biochemical staining such as Orange G, which is also used for analysing archaeological residues (Hayes et al. 2017).

At low and high magnification, residues were documented using a Zeiss Axiocam 506 High Definition Colour Camera.

\section{Use Wear Analysis}

The analysis and description of use wear at low and high magnification were based upon well-established methodologies and terminologies (Adams et al. 2006; Dubreuil et al. 2015; Dubreuil and Savage 2014; Hamon and Plisson 2009). Use wear developed on the surface of the experimental replicas was observed at low $(\times 0.70-\times 100)$ and high $(\times 100-\times 500)$ magnifications (Rots 2010; Tringham et al. 1974; van Gijn 2010). Macro wear, consisting in the topography of the microrelief, intergranular space, grain morphology, macro striations and pitting (Dubreuil et al. 2015; Dubreuil and Savage 2014; Hamon and Plisson 2009), was observed and described using a Zeiss AxioZoom 
V16 motorised digital stereoscope. Micro polish, abrasions and micro striations (Dubreuil et al. 2015; Hayes et al. 2018) were observed and described using a Zeiss AxioScope metallographic microscope with magnifications up to $\times 500$. Given the dimensions of the replicas, not allowing their direct observation under the metallographic microscope, high resolution silicon casts of the utilized areas were taken using Provil Novo Light Fast Set (Heraeus Kulzer Inc.) (Banks and Kay 2003; Macdonald et al. 2018; Pedergnana and Ollé 2016).

Tools were washed after the observation at low magnification and the residue sampling, using hot demineralized water and a $2 \%$ neutral phosphate-free detergent solution (Derquim ()), then rinsed with fresh demineralized water (Pedergnana and Ollé 2016). Macro traces were recorded using a Zeiss Axiocam 506 High Definition Colour Camera, while micro wear pictures were taken using a Zeiss 305 High Definition Colour Camera.

\section{Results}

\section{Residue Spatial Distribution}

The analysis of the morphometry (area and perimeter) and spatial features (DC, DE, DUA and SDE) allowed us to identify several patterns associated with the performed activity, the worked material and the active/passive role of the tool (Figs. 3, 4 and 5).

Within GSTs used as passive elements, plant food grinding resulted in the largest patches of residues (mean area $0.22 \mathrm{~cm}^{2}$ ) well distributed across the utilized surface of the tool, as indicated by the values of DC, DE and DUA (Supplementary Tables S1 and S2). The broad dispersion of residues is also shown by the recorded SDE exhibiting a mean area of area of $19.5 \mathrm{~cm}^{2}$. Polishing of dry bone resulted in small patches of residual matter (mean area of $0.03 \mathrm{~cm}^{2}$ ). The values of DC, DE and DUA indicate a wide dispersion of residue across the surface of the GST replica, as also shown by the SDE area $\left(12.6 \mathrm{~cm}^{2}\right)$. As for pounding activities, in both cases (splitting metapodials and hazelnut cracking), the dimensions of the residue patches share similar values (Supplementary Tables S1 and S2), while differences are recorded in their distribution across the surface. The residual matter related to metapodial splitting is widely dispersed as indicated by the values of DC, DE and DUA and by the SDE area $\left(19.5 \mathrm{~cm}^{2}\right)$. Conversely, residues originating from the cracking of hazelnuts appear well concentrated (SDE area $3.58 \mathrm{~cm}^{2}$ ) and localized in proximity of the centre of the tool surface and its actual used area (Supplementary Table S2).

Among the GST replicas used as active elements, the largest patches of residual matter are recorded over the surface of the tools used for pounding and softening (mean area $0.05 \mathrm{~cm}^{2}$ ). Dry hide softening produced a broader distribution of residues across the surface, as shown by the values of DC, DE and DUA and by the SDE area $\left(5.9 \mathrm{~cm}^{2}\right)$ (Supplementary Tables S1 and S3). The residual matter from tendon pounding and hazelnut cracking appears clustered in proximity of the used surface and its geometric centre (Supplementary Table S3). This behaviour is also confirmed by the similar recorded SDE areas, $4.04 \mathrm{~cm}^{2}$ (pounding tendons) and $4.05 \mathrm{~cm}^{2}$ (opening hazelnuts).

Smaller patches of residues are instead recorded across the tools used for grinding (mean area $0.04 \mathrm{~cm}^{2}$ ). Notable differences emerge between the dimensions of residue 


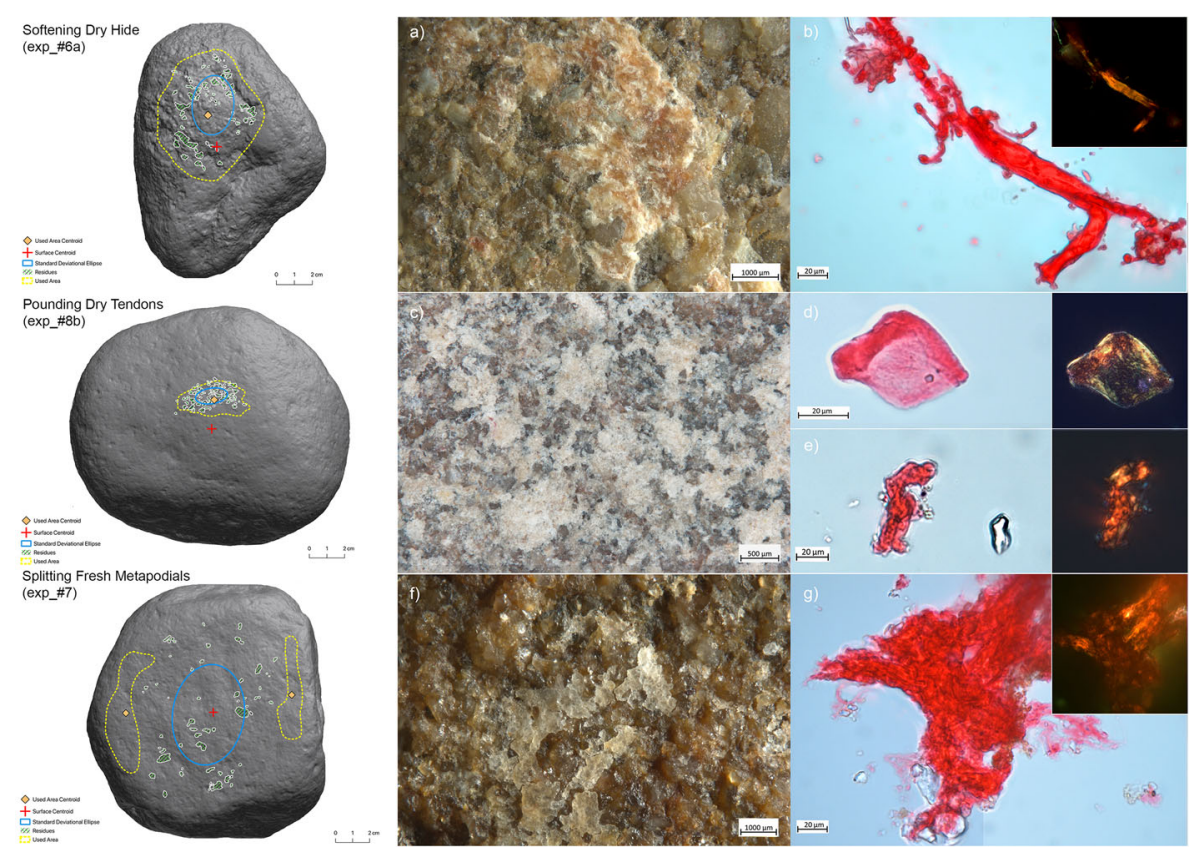

Fig. 3 Spatial distribution of residues across the utilized surface of the passive tools and residual matter observed at low and high magnifications. a Macro residues associated with the softening of dry hide; b hide micro residues stained with PSR; c macro residues associated with the pounding of dry tendons; d,e tendon micro residues stained with PSR; $\mathbf{f}$ Macro residues associated with the splitting of fresh metapodials; $\mathbf{g}$ micro residues from bone splitting stained with PSR

patches originating from grinding wild grass grains (mean area $0.07 \mathrm{~cm}^{2}$ ) and oat grains $\left(0.01 \mathrm{~cm}^{2}\right)$. Such a difference is not recorded in the spatial distribution of residual matter across the surface, which, in both cases, is localized in the proximity of the used area (Supplementary Table S3). Even though the localization of residues (close to the used area) is similar, residue patches resulting from wild grass grain grinding appear more dispersed than the ones related to oat grains, as indicated by the recorded SDE area $\left(2.01 \mathrm{~cm}^{2} ; 1.4 \mathrm{~cm}^{2}\right)$.

\section{Residue Morphologies}

Differences in residue appearance and distribution were recorded and related to the variety of activities performed and materials processed with the sandstone tools (Table 2).

Dry hide softening leaves macro residues such as beige collagen fibres, which appear as compressed, sometimes translucent, compound. Due to the prolonged friction, a thick crusty surface, amber in colour, can develop on the highest points of the stone tool and merge with the lower areas of the stone matrix. Within such thick crust, fibres are visible as well as linear features (Fig. 3a). In transmitted light, long, sometimes twisted, collagen fibres are observed. When stained with PSR, all the fibres turn into vivid red, and, when observed in cross-polarized light, they show an enhanced yellow-orange birefringence, typical of type I collagen (Fig. 3b).

Tendon processing generates a white powder residue with a spot-like distribution. Similarly to what was observed for seeds processing, when compacted, the 


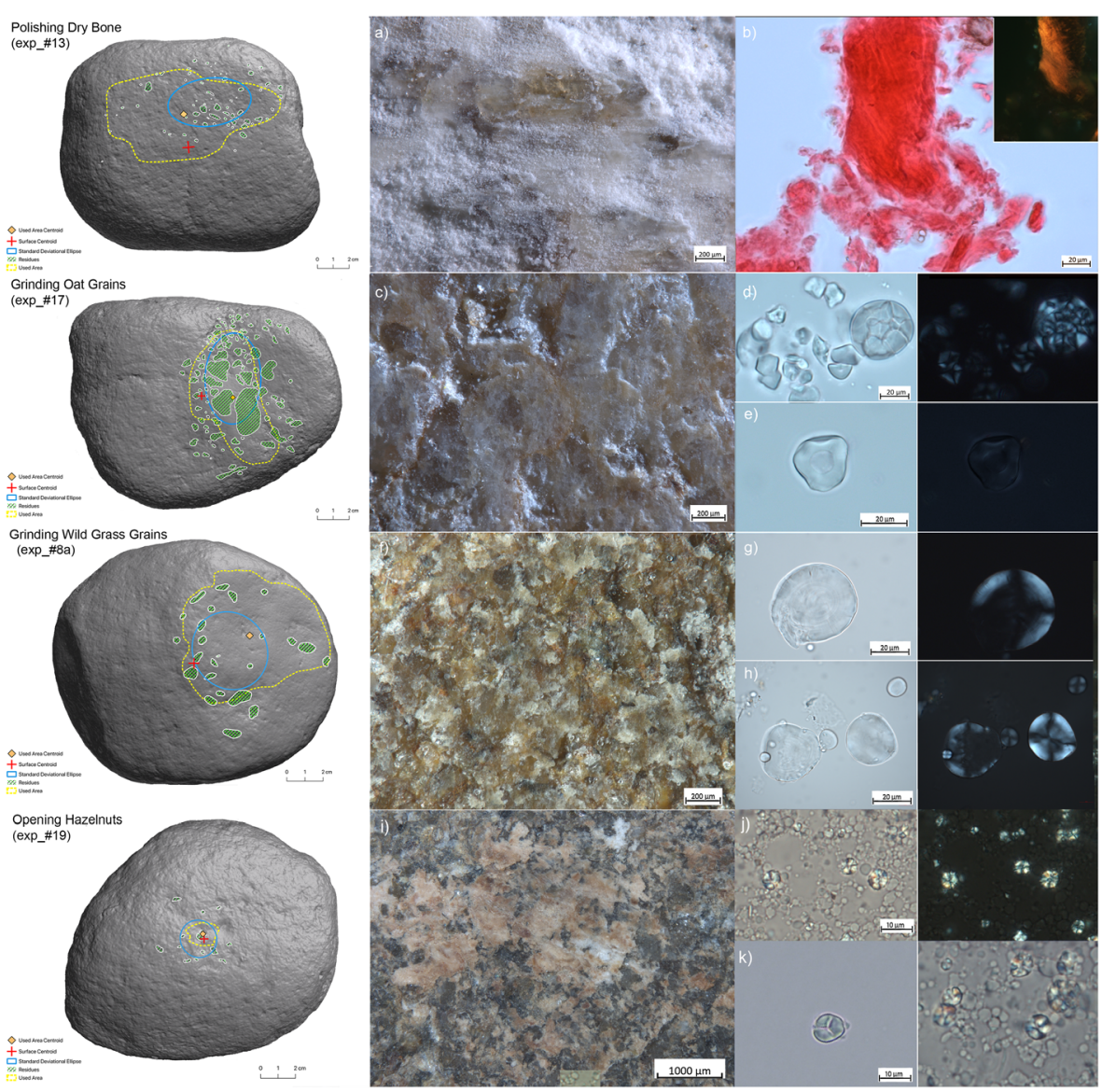

Fig. 4 Spatial distribution of residues across the utilized surface of the active tools and residual matter observed at low and high magnifications. a Macro residues associated with the abrasion of dry bone; $\mathbf{b}$ bone micro residues stained with PSR; c Macro residues associated with grinding of oat (Avena barbata); d,e Avena barbata starch granules; f Macro residues associated with grinding of wild grass grains (Aegilops ventricosa); g,h Aegilops ventricosa starch granules; i Macro residues associated with hazelnut cracking (Corylus avellana); $\mathbf{j}, \mathbf{k}$ Corylus avellana starch granules

residue appears as a film with a spot-like distribution (Fig. 3c). Highly processed patches of residue show a yellowish colour, and collagen structures can be visible in the compressed residual matrix at higher magnification. Flat collagen tissues are recorded as well as single or tightly clustered collagen fibres, characterized by a parallel to wavy appearance. When stained with PSR, all the structures turn into vivid red. However, in cross-polarized light, different birefringence patterns are recorded: a yellow-green colour, typical of type III collagen, characterizes the flat collagen tissues (Fig. 3d), while the single or tightly clustered fibres show yelloworange colour, typical of type I collagen (Fig. 3e).

Splitting metapodials left patches of a greasy film across the central area and the edges of the tool. Such patches incorporate compressed periosteum mixed with fat and collagen fibres (Fig. 3f). Amorphous fat-rich yellowish compound appears distributed in patches across the central area of the tool and characterized by mud-cracked 


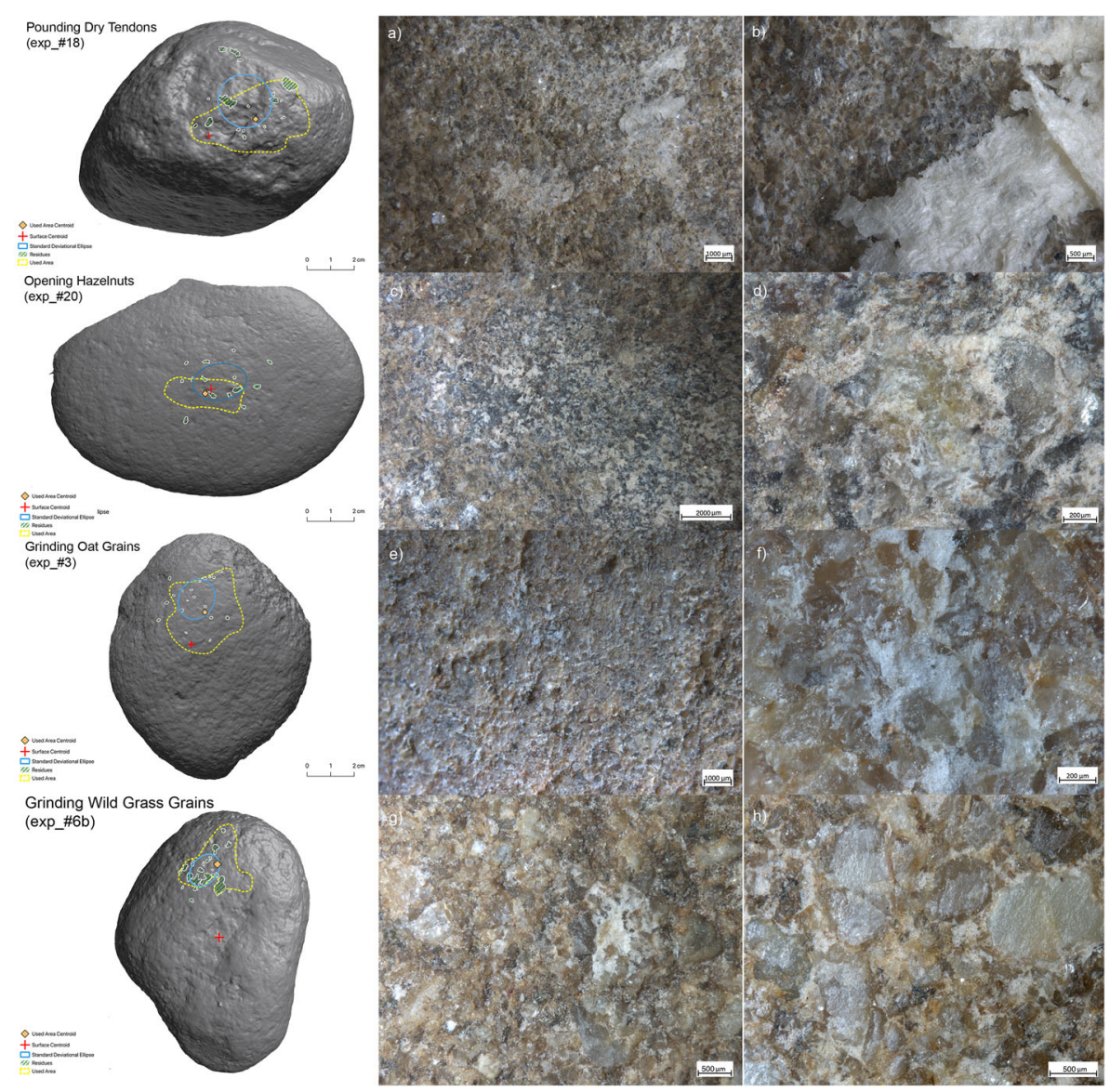

Fig. 5 Spatial distribution of residues across the utilized surface of active tools and residual matter observed at low and high magnifications. a,b Macro residues associated with the pounding of dry tendons; c,d Macro residues associated with hazelnut cracking; e,f Macro residues associated with oat grinding; g,h Macro residues associated with wild grass grain grinding

appearance. Isolated collagen fibres are identified. In transmitted light, structures appear as amorphous aggregates of material with long and twisted fibres, turning into vivid red when stained with PSR. In cross-polarized light, residues display a strong birefringent yellow colour, typical of type I collagen (Fig. 3g).

Dry bone polishing generates compact white powder across the entire surface of the tool. As a result of the prolonged friction applied during the use, glossy yellowish spots with a translucent and cracked appearance can develop, together with linear features indicating the gesture performed (Fig. 4a). In transmitted light, packed groups of thick parallel collagen fibres are observed. At $\times 1000$, they show a reduced birefringence and internal banding patterns within the fibres. When stained with PSR, all structures turn into vivid red with a strong yellow-orange birefringence, typical colour of type I collagen, when observed in cross-polarized light (Fig. 4b).

Oat grain grinding leaves a discontinuous smooth film adhering the stone surface, which connects the crystal grains into a smooth flat surface. Sometimes, the residues 


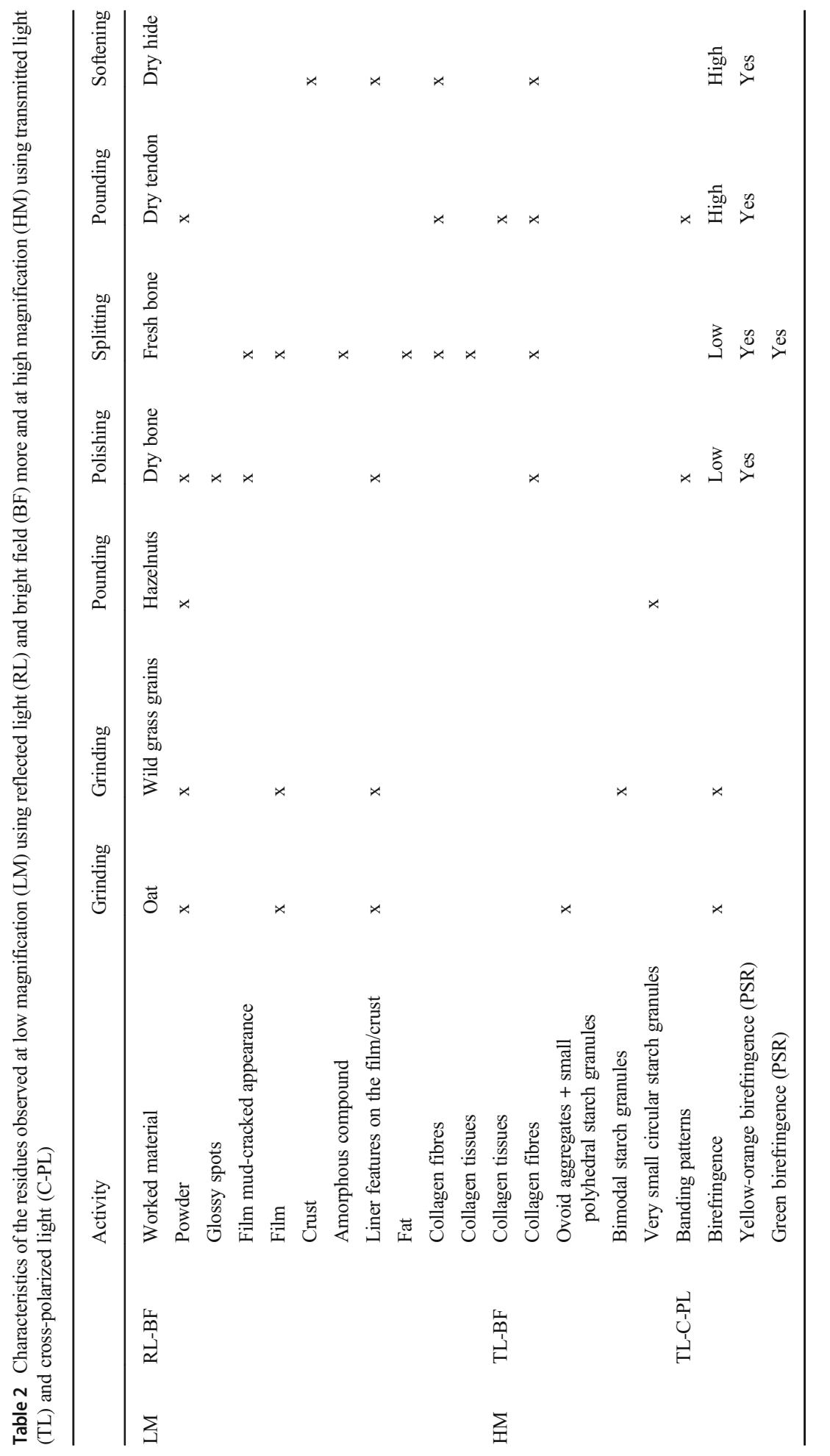


merge with the stone matrix so that distinguishing the raw material from the residual substrate becomes difficult (Zupancich and Cristiani 2020). Depressions appear at low magnification within the residual layer, filled with starch-rich powder and other vegetal structures (Fig. 4c). Only a few intact ovoid aggregates formed by numerous polyhedral individual or clustered grains, typical of the genus Avena, are identified on the experimental grinding stone, probably due to the intense processing of the oat grains (Fig. 4d). On the contrary, small irregular/polyhedral starch granules (main axis ranging from 5 to $20 \mu \mathrm{m}$ in our sample) are most represented and characterized by a flat or irregularly concave facet, a centric hilum and an extinction cross distorted by the facets. In the case of damaged granules, the hilum could appear enlarged and sunken (Fig. 4e).

Wild grain grass processing causes a translucent film to be deposited on the quartz grains. The latter appears yellowish in some parts and sometimes striated. A powdery residue, rich in starch and other vegetal structures, is recorded in the depression of the stone and can appear within the film (Fig. 4f). Aegilops ventricosa starch grains are characterized by a bimodal distribution with large, round-shape, A-type granules and much smaller circular and sub-oval and shaped B-type granules (Evershed et al. 1991; Piperno et al. 2004; Stoddard 1999). A-type granules (ranging between 21.1 and $41.7 \mu \mathrm{m}$ in maximum dimensions in our sample; mean size of $31 \mu \mathrm{m}$ ) are round to sub-oval 2D shape, lenticular 3D shape with equatorial groove always visible, central hilum and numerous lamellae (known as A-type) (Fig. 4g,h); B-type granules are very small spherical and sub-spherical granules with a central hilum ( $\leq 10 \mu \mathrm{m}$, known as B-type) (Fig. 4h).

Generally, in cross-polarized light, type-A granules show a defined extinction cross and visible lamellae, exception made for the larger granules characterized by weak birefringence and a poorly defined extinction cross (Fig. 4h). The state of preservation of starch granules can vary, due to prolonged processing. Some granules appear intact, while the larger ones are swollen, split and/or cracked with no birefringence preserved (Fig. 4g).

Cracking Corylus avellana nuts leaves a small quantity of a greasy, powdery residue, sometimes mixed with other vegetal structures. Such residue is compressed into the depressions of the stone matrix and distributed in patches across the used surface (Fig. $4 \mathrm{i}$ and $5 \mathrm{c}-\mathrm{d})$. Few and very small starch granules were retrieved from the experimental stones. They are characterized by a circular shape (ranging between 10.1 and $7.5 \mu \mathrm{m}$ in maximum dimensions in our sample; mean size of $8.8 \mu \mathrm{m}$ ), a centric slightly open hilum and perpendicular extinction cross (Fig. $4 \mathrm{j}-\mathrm{k}$ ). The lower carbohydrate content of hazelnuts, when compared with other fruits or grass grains, could justify the low recovery of starch granules on both passive and active tools (Brufau et al. 2006).

\section{Use Wear Analysis}

The surfaces of the experimental replicas were observed before and after use to identify distinctive patterns of surface modification associated with different activities and worked materials (Figs. 6 and 7). At low magnification, the modifications of the microrelief and crystal grains are highly informative about the gesture performed and the hardness of the worked material. At high magnification, the distribution and morphology (i.e. texture and topography) of the micro polish, along with the microscopic modification of the crystal grains (i.e. abrasion and micro-fracturing), allow for a more specific interpretation of the worked substances. 

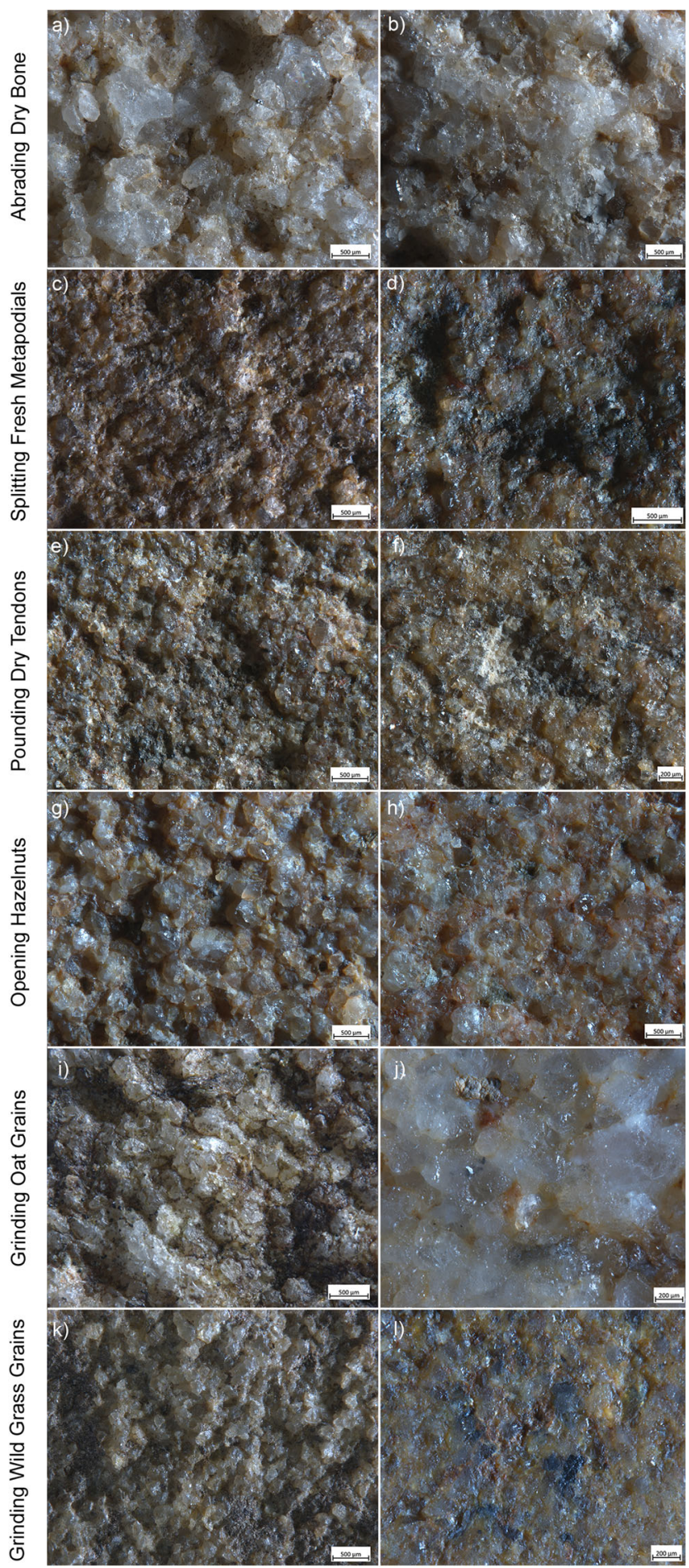

Fig. 6 Surfaces of GST replicas used as passive tools as they appear before (a,c,e, $, \mathbf{g}, \mathbf{i}, \mathbf{k})$ and after $(\mathbf{b}, \mathbf{d}, \mathbf{f}, \mathbf{h}, \mathbf{j}, \mathbf{l})$ use 

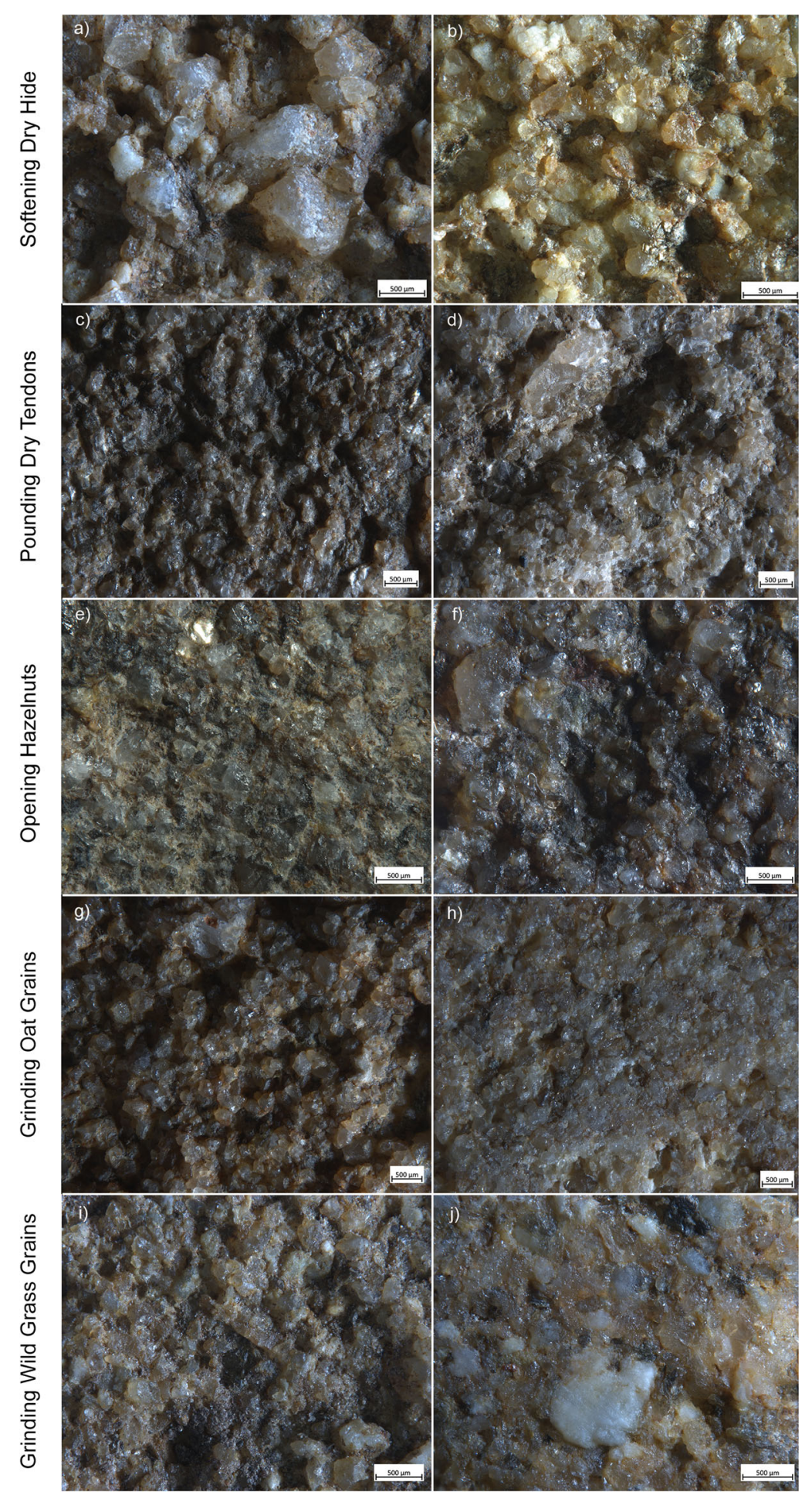

Fig. 7 Surfaces of GST replicas used as active tools as they appear before (a,c,e,g,i) and after $(\mathbf{b}, \mathbf{d}, \mathbf{f}, \mathbf{h}, \mathbf{j})$ use

\section{Springer}


Dry hide softening generates a sinuous microrelief of the utilized areas of the surface. At low magnification, a high degree of rounding affects the edges of the grain crystals, while the surfaces appear abraded. Few grain removals are also visible, while no linear features or pits are recorded (Fig. 8a). At high magnifications, a micro polish characterized by a smooth texture and a domed topography affects both the matrix and parts of the crystal grains. In some instances, the polish topography appears flat (Fig. 8b). A high degree of micro rounding of the edges of the grains is also visible.

Dry tendon pounding produces an irregular surface microrelief on both the active and passive elements. At low magnification, the crystal grains are characterized by micro fractures affecting both their edges and surfaces, which appear abraded (Fig. 8c; Fig. 9g). Pits, resulting from the removal of the crystal grains, are scattered across the utilized area and are characterized by an irregular shape and a "V" cross-section (Fig. 8c, Fig. 9g). Linear features are not recorded. At high magnification, most of the visible use-related damage affects the crystal grains. Fracture and abrasion of the grain surface are frequent and associated with a micro polish characterized by a smooth texture and domed topography (Fig. 8d, Fig. 9h).

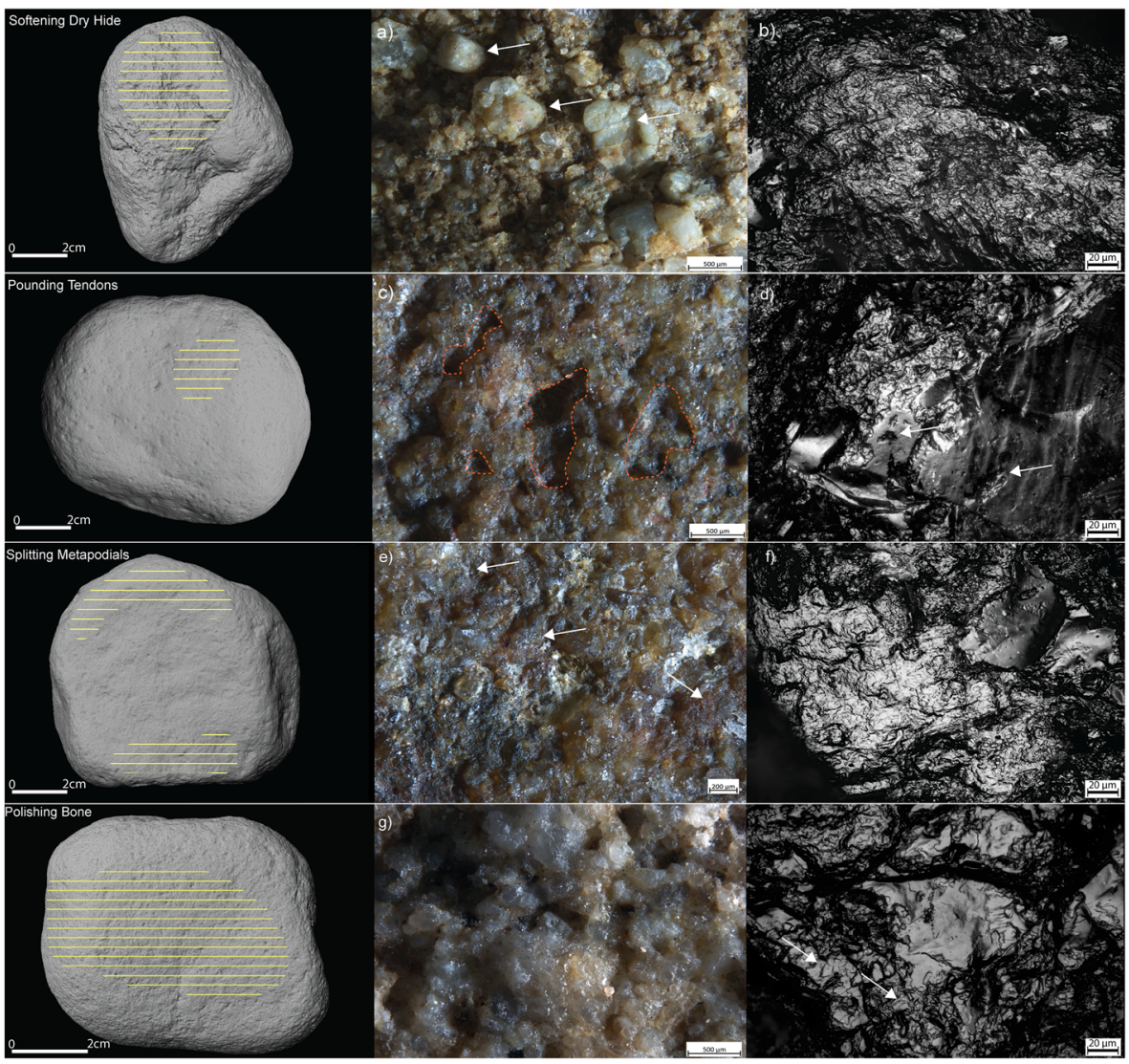

Fig. 8 Macro and micro wear developed through the processing of animal matters. a,b Softening of dry hide; $\mathbf{c}, \mathbf{d}$ pounding of dry tendons; e,f splitting of fresh metapodials; $\mathbf{g}, \mathbf{h}$ polishing of dry bone. The yellow lines indicate the utilized area of the surface, orange dashed lines are used to highlight pits, and white arrows indicate specific patterns of grain modifications. Micro wear pictures are taken at $\times 500$ 


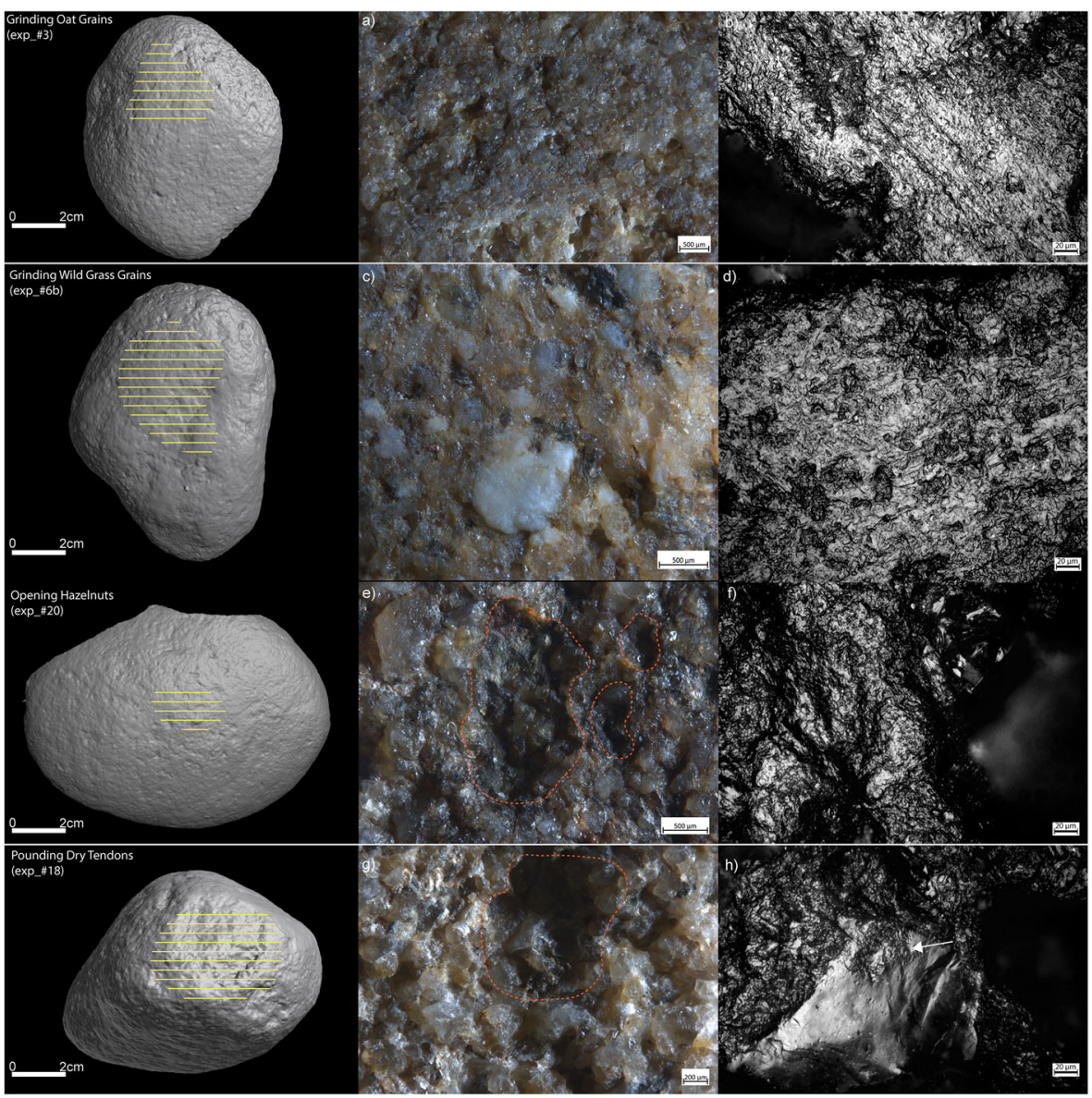

Fig. 9 Macro and micro wear developed on active tools through the processing of animal and vegetal matters. a,b Grinding of oat grains (Avena barbata); c,d grinding of wild grass grains (Aegilops ventricosa); e,f hazelnut cracking (Corylus avellana); g,h pounding dry tendons. The yellow lines indicate the utilized area of the surface, orange dashed lines are used to highlight pits, and white arrows indicate specific patterns of grain modifications. Micro wear pictures are taken at $\times 500$

Splitting metapodials generated the development of a sinuous microrelief of the used area. At low magnification, the surface of the crystal grains is abraded, and sporadic micro fractures are recorded. The edges of the crystals appear sharp without relevant use modifications. Pits and linear features are not recorded (Fig. 8e). At high magnifications, a micro polish characterized by a smooth texture and a domed topography developed over the matrix, affecting only sporadically the edges of the crystal grains (Fig. 8f). The grain surfaces are characterized by micro fractures and abrasions.

Polishing dry bone resulted in a sinuous microrelief of the utilized surface area, characterized by sporadic grain removals. At low magnification, the grains are levelled, and, in several cases, their surfaces appear abraded (Fig. 8g). The edges of the crystal grains are relatively sharp, and a medium degree of rounding is recorded. Across the surface, neither macro striations nor pits are observed. At high magnifications, a micro polish with a smooth texture and a domed to flat topography is visible on the matrix 
and the crystal grains (Fig. 8h). Where more developed, the polish topography is also characterized by micro pits. Linear features with mixed orientations are also visible across the grain surface, while a medium to a high degree of micro rounding is recorded over their edges.

Grinding of oat grains resulted in a flat microrelief of the used surface on both the active and passive elements. At low magnification, grains appear levelled, and their edges exhibit a high degree of rounding (Fig. 9a, Fig. 10a). Narrow linear features are rare on the surface of the crystal grains. Neither pits nor grain extractions are recorded. At high magnification, the micro polish is characterized by a smooth texture and a domed to flat topography (Fig. 9b, Fig. 10b). Micro polish develops across the matrix and the crystals, which appear heavily embedded within the polished surface.

Both the active and passive elements employed in the grinding of wild grass grains are characterized by a flat microrelief of the utilized area. At low magnifications, the crystal grains are levelled (Fig. 9c, Fig. 10c). Several short and narrow linear features are visible across the utilized area along with sporadic extracted grains (Fig. 9c). At high magnification, the observed micro polish is characterized by a smooth texture and a flat topography and affects mostly the matrix (Fig. 9d, Fig. 10d). A developed micro rounding of the crystal grains is recorded together with occasional long and deep micro striations.

Hazelnut cracking generated a small $(<20 \mathrm{~mm})$ depression over the portion of the surface where the nuts were opened. At low magnifications, two different types of traces were visible, one developed over the edges and walls of the pit, the other over the bottom

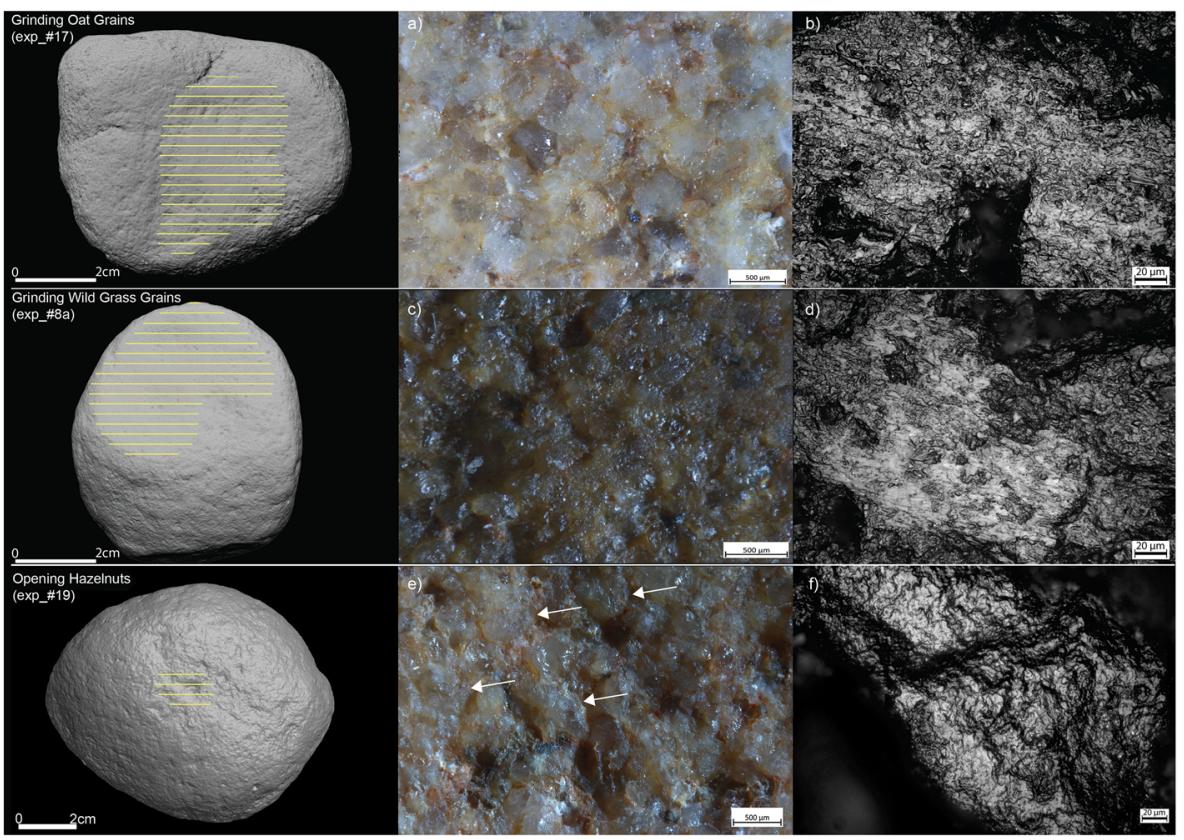

Fig. 10 Macro and micro wear developed through the processing of vegetal matters. a,b Grinding of oat grains (Avena barbata); c,d grinding of wild grass grains (Aegilops ventricosa); $\mathbf{e}, \mathbf{f}$ hazelnut cracking (Corylus avellana). The yellow lines indicate the utilized area of the surface, and white arrows indicate specific patterns of grain modifications. Micro wear pictures are taken at $\times 500$ 
of the depression. Across the walls of the pit, the crystal grains appear abraded, while their edges are sharp. The bottom of the depressions is characterized by a sinuous microrelief (Fig. 10e). The surfaces of the crystal grains appear fractured, and several grain extractions are visible. On the active tool, small pits are visible across the utilized area (Fig. 9e). The grains surfaces are abraded. Fractures are also evident over the surfaces of the larger grains (Fig. 9e). On both the active and passive elements, no linear features are visible at low magnifications. At high magnifications, spots of polish with a smooth texture and a domed topography are observed on both tools (Fig. 9f and 10f), following the same patterns observed by Pardoe et al. (2019).

\section{Discussion}

In this paper, we explored the potential of a multi-level approach combining qualitative use wear traces and residue analyses to residue spatial distribution for reconstructing the functions of ancient sandstone GSTs. Distinctive use wear modifications, residue morphologies and spatial distribution patterns were associated with the utilization of GSTs.

Use Wear Modifications Use wear features identified for different activities and processed materials are in accordance with patterns of surface modifications already described on sandstone GSTs by other scholars (Adams 1999; Delgado-Raack and Risch 2008; Hamon 2008; Hamon and Plisson 2009; Hayes et al. 2018; Pardoe et al. 2019; Zupancich et al. 2019). At low magnification, a differentiation between tools used to process vegetal and animal substances is possible based on the microrelief. In particular, seed grinding develops a flat microrelief of the surface, while hazelnut cracking resulted in a sinuous surface microrelief. Processing of animal tissues results in a sinuous or irregular surface microrelief with the former associated with resting percussion and the latter to thrusting percussion.

The modification of grains further allows a differentiation at low magnification within our experimental sample. In the case of plant foods, an extensive flattening of the crystal grains is observed for oat and wild grass grains processing, while an abrasion of the grain surface is generated after hazelnut cracking. Abrasion and fracturing of the grain surface and edges are frequently observed across the tools utilized to process animal tissues. Contrary to the surface microrelief, such difference should be associated with the worked material rather than the gesture performed as resting percussion activities involving animal and vegetal matter alters grains differently. Indeed, in the case of seed grinding, the contact between the active and passive tool is not strongly mediated by the worked substance as in the case of animal matters processed through back and forth movements. Specifically, during bone polishing and dry hide softening activities, the formation of a residual layer between the worked substance and the tool surface reduces the degree of levelling of the crystal grains. A different mechanism is observed for the tool used to split metapodials, as the bone itself absorbs the force generated by the percussion, while the subsequent friction with bone causes the abrasion of the crystals (see also de la Torre et al. 2013). Surface grain abrasion is also documented after hazelnut cracking. Similarly to what observed for metapodial splitting, this behaviour can be explained as nut shells absorbed part of the thrusting 
force, with the friction between the nut shell and the crystal surface resulting in the abrasion of this latter.

On the contrary, this damage pattern is not recorded in the case of tendon pounding, where the fracturing of the crystals is frequent as the worked substance does not mediate the contact between the active and passive tools.

At high magnifications, differences in micro polish location and morphology (i.e. texture and topography) are identified. Micro polish affects both the matrix and the crystal grains in the case of seed grinding and pounding, bone polishing and dry hide softening. Conversely, a micro polish is produced over the matrix only in the case of metapodials splitting and over the crystal grains, in the case of tendons pounding.

A generally smooth texture of the micro polish is observed while its topography is variable. The latter ranges from domed to flat in the case of vegetal matters. Moreover, a differentiation between the processing of oat and wild grass grains is suggested based on the presence of linear features, frequent in the case of wild grass grains processing but not recorded after oat grain grinding. In the case of hazelnut cracking, the development of smooth domed polish is often associated with medium sized pits visible across the surface of the crystal grains.

The topography of the micro polish is generally domed in the case of animal tissue processing. Just in the case of bone polishing, micro pits are visible across the polished areas.

Finally, an abrasion of the crystal grains edges and/or surfaces is characteristic when processing animal substances, with the only exception of dry hide softening. Furthermore, in the case of tools utilized in thrusting percussion activities, it is not uncommon to find the abrasion of the crystals in association with micro fractures.

No specific differences were recorded in the characteristics of macro and micro use wear between active and passive tools. The only differences were observed on the set of replicas used to crack hazelnuts, where the large depression visible in the passive element was not recorded on the active one. Such a low variability in the traces observed on active and passive tools suggests that when a differentiation has to be made in regard of the role played by a given implement, this should rely on the morphology (i.e. shape and dimensions) of the tool rather than on the use wear. Such a conclusion could be tested further by applying quantitative techniques (e.g. surface texture analyses), which may provide other discriminant variables (Ibáñez et al. 2014, 2019).

We also noticed that certain types of traces, such as the fracturing of the crystal grain surfaces, are commonly observed in the processing of both animal and vegetal matters; hence, they cannot be considered reliable for inferring the worked material. However, they can be informative about the gesture performed (Table 3) as they are only observed on the tools utilized in thrusting percussion activities, such as tendon pounding and hazelnut opening.

Residue Morphology and Spatial Distribution Patterns The nature (i.e. vegetal, animal) of the residues can be easily assessed at low magnification due to their diagnostic distribution and appearance. We noticed that prolonged activity can alter the residue structure, especially at high magnification. In the case of animal tissue processing, the different birefringence patterns produced, under cross-polarized light, by PSR biochemical staining, and the evaluation of the morphologies of the different collagen tissues 


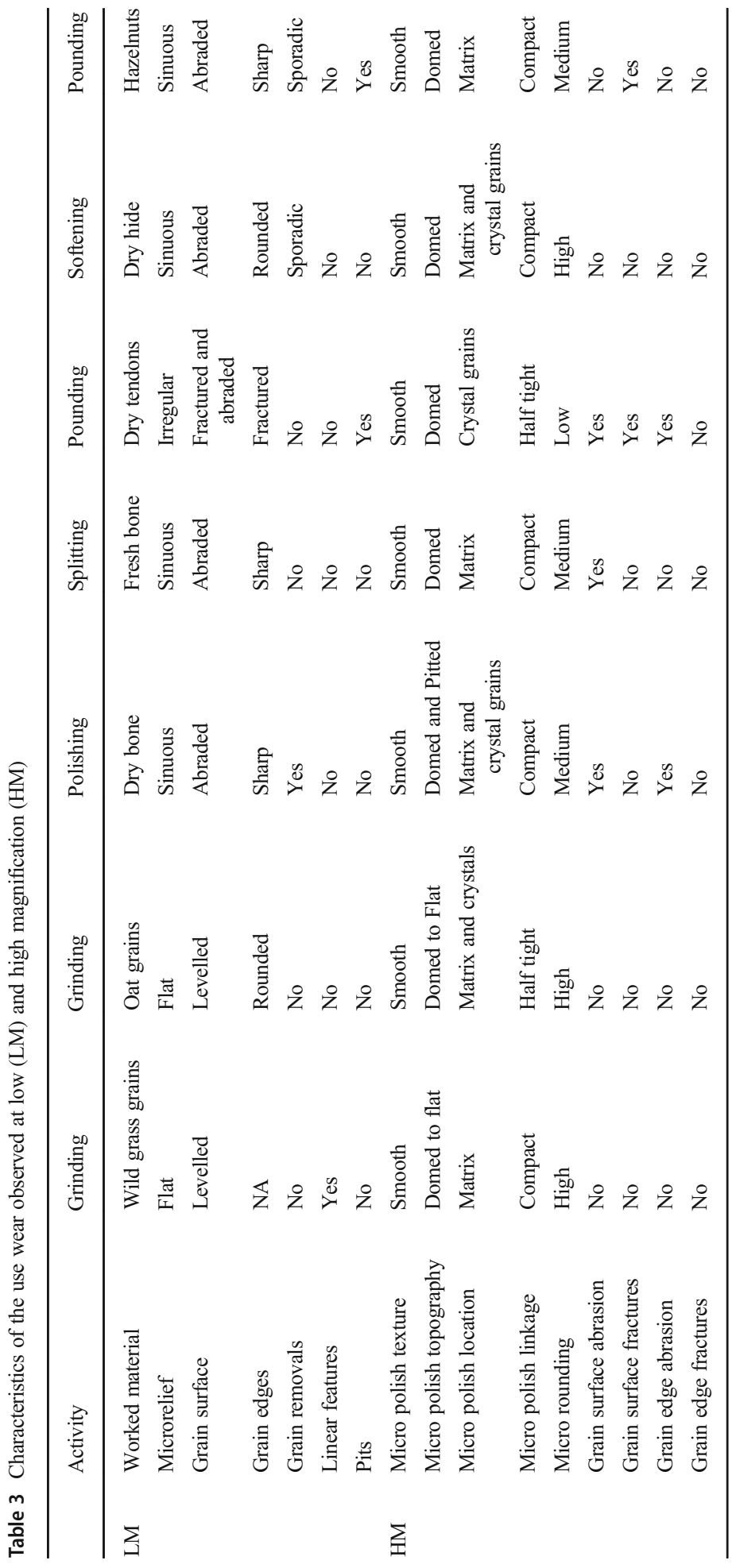


can be particularly useful for distinguishing highly damaged bone, skin and tendon residues. As for grain processing, starch granules sampled along the most used areas can show alteration of their morphology and diagnostic features, as already recognized by Zupancich et al. (2019).

Differences in the morphometrics and the distribution of residues emerge from our analysis and are related to the pattern of surface modification resulting from the activity, worked substance as well as the role played by the tool (Table 4 and 5). On passive elements, differences in the distribution of residues are related to the kind of surface modification affecting the used area of the GSTs. This is particularly evident in the case of seed grinding and bone polishing, where the heavy rounding and the levelling of the surface microrelief facilitate the widespread of residual matter across the surface of the tool. On the contrary, tools utilized for pounding see the formation of pits and/or the detachment of grains from the surface. This results in a rough, irregular microrelief, blocking the spread of residues outside the limits of the utilized area. An exception to this pattern is given by the experimental replica used to split metapodials where residues are well spread across the surface (SDE mean area $19.5 \mathrm{~cm}^{2}$ ) and distant from the utilized areas $(5.79 \mathrm{~cm})$. This can be explained by the fact that even though the metapodials rested over the edges of the GST, they also came in contact with the central area of the tool, resulting in the wide distribution of residual matter across the surface.

Among the replicas used as active elements, a different pattern is recorded in the spatial distribution of residues. Contrary to what is recorded on passive tools, residues originating from resting percussion activities appear concentrated across the surface (SDE mean area $3.1 \mathrm{~cm}^{2}$ ) and localized near to the used area mean (DUA $1.13 \mathrm{~cm}$ ). This could be explained considering that only a small portion of the active surface is used, resulting in a minimal dispersion of residual matter. Moreover, the relationship between residue distribution and surface modification appears clear also in the case of

Table 4 Summary table on the morphometry and spatial distribution of residual matter recorded for passive and active elements

\begin{tabular}{|c|c|c|c|c|c|}
\hline \multicolumn{6}{|l|}{ Passive elements } \\
\hline n.335 & Mean & Std. Dev. & Min. & Median & Max. \\
\hline Area $\left(\mathrm{cm}^{2}\right)$ & 0.11 & 0.33 & 0.00 & 0.04 & 5.12 \\
\hline Perimeter $(\mathrm{cm})$ & 1.07 & 0.91 & 0.20 & 0.82 & 9.29 \\
\hline Distance from surface centre $(\mathrm{cm})$ & 3.46 & 1.72 & 0.25 & 3.35 & 7.84 \\
\hline Distance from surface edges $(\mathrm{cm})$ & 4.01 & 1.48 & 0.56 & 4.23 & 7.39 \\
\hline Distance from surface used area $(\mathrm{cm})$ & 3.32 & 2.08 & 0.10 & 3.07 & 9.46 \\
\hline \multicolumn{6}{|l|}{ Active elements } \\
\hline n. 131 & Mean & Std. Dev. & Min & Median & Max \\
\hline Area $\left(\mathrm{cm}^{2}\right)$ & 0.05 & 0.06 & 0.00 & 0.03 & 0.41 \\
\hline Perimeter $(\mathrm{cm})$ & 0.81 & 0.57 & 0.24 & 0.66 & 3.66 \\
\hline Distance from surface centre $(\mathrm{cm})$ & 2.45 & 1.42 & 0.00 & 2.48 & 5.68 \\
\hline Distance from surface edges $(\mathrm{cm})$ & 3.09 & 0.98 & 1.00 & 3.17 & 5.24 \\
\hline Distance from surface used area $(\mathrm{cm})$ & 1.66 & 0.76 & 0.09 & 1.64 & 3.68 \\
\hline
\end{tabular}




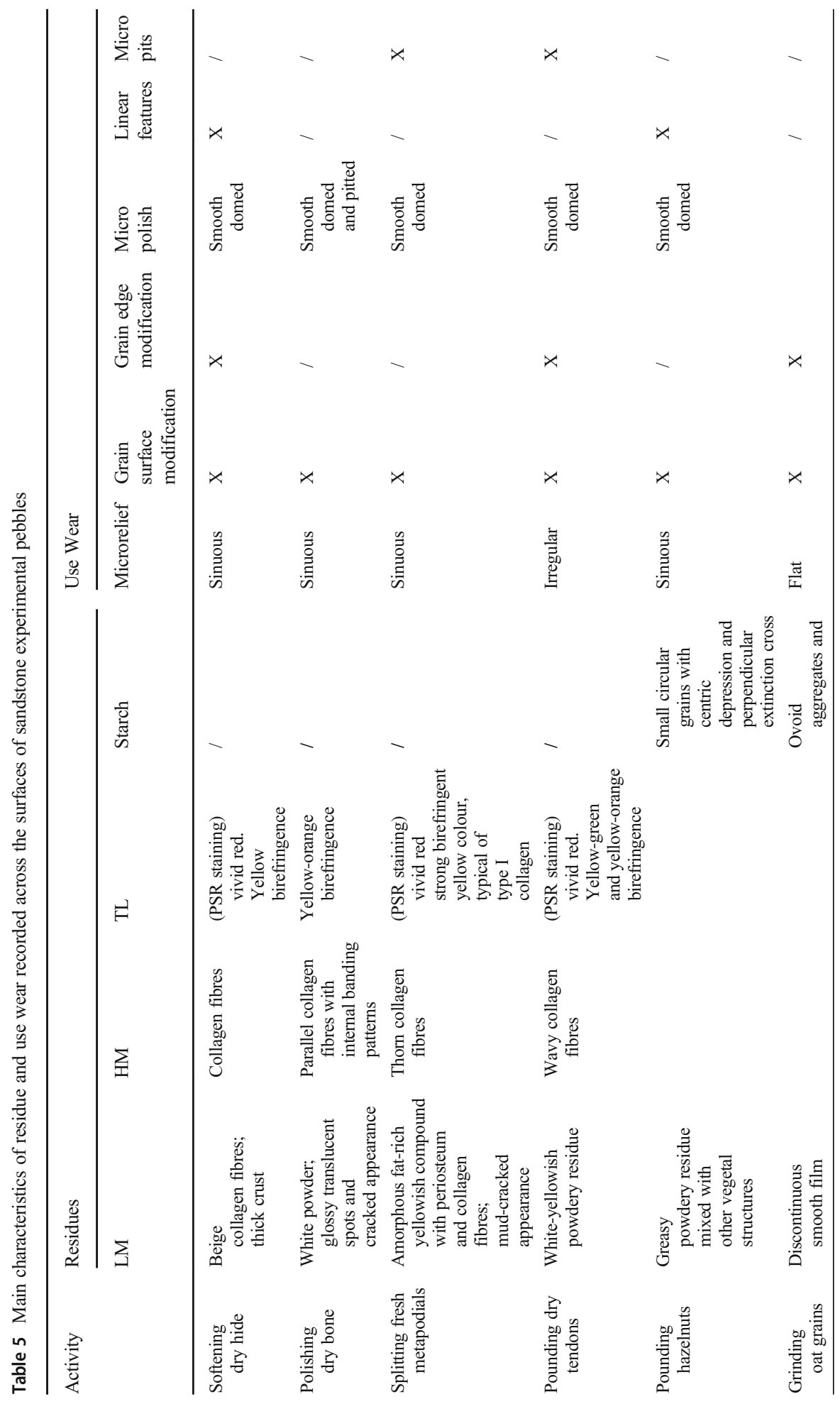




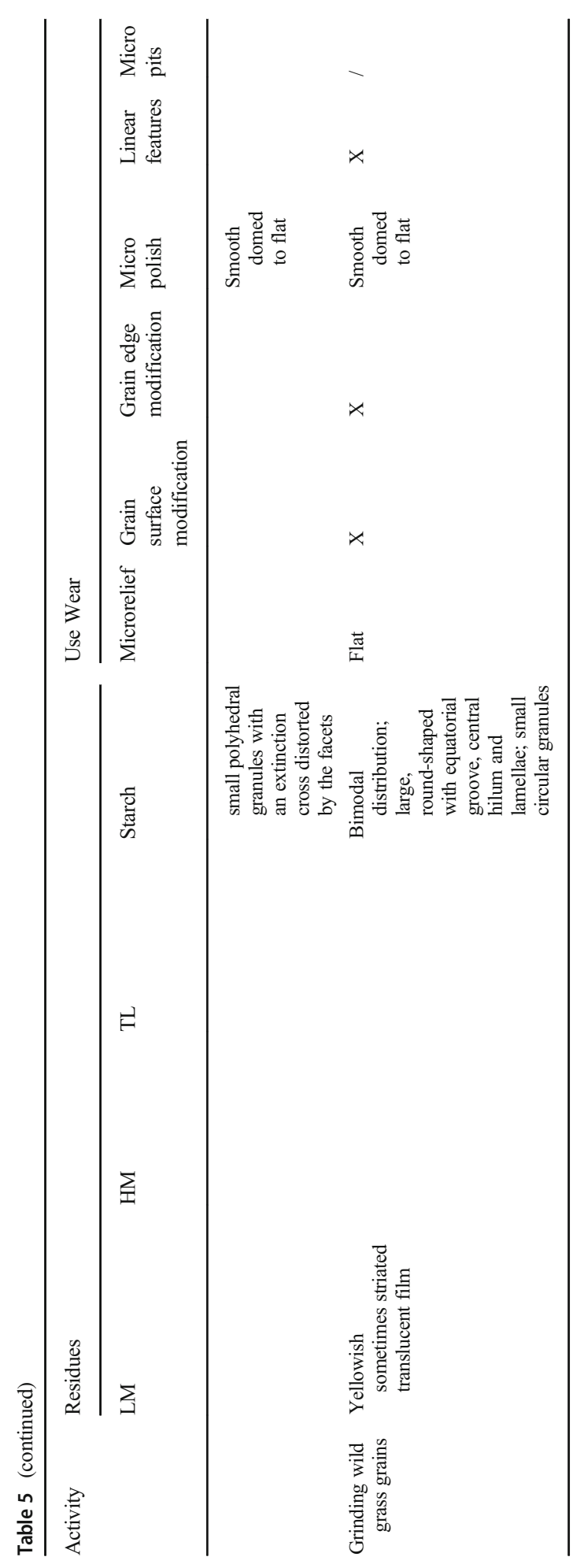


active tools as demonstrated by the replica utilized to process dry hide. Here, the residues seem more dispersed across the surface of the tool (SDE mean area $5.9 \mathrm{~cm}^{2}$ ) and more distant from the utilized portion of the surface (mean DUA $2.01 \mathrm{~cm}$ ), when compared with the values recorded on the tools used to grind oat and wild grass grains. The dispersion of residual matter far from the centre of the used area can be explained by the frequent extraction of grains from the utilized area of the surface, and the consequent loss of the residues.

Residues adhering to active elements used in thrusting percussion appear less clustered and more dispersed across the surface (mean SDE area $4.02 \mathrm{~cm}^{2}$ ) when compared with the ones originating from the use of active tools in resting percussion activities. In this case, it is possible that during pounding, the contact between the tool and the worked material affected different areas of the tool surface, resulting in a wider dispersion of residual matter.

In terms of morphometry of the residue patches, passive elements exhibit overall larger specimens (mean area $0.11 \mathrm{~cm}^{2}$ ) than the ones adhering on the surfaces of active tools (mean area $0.05 \mathrm{~cm}^{2}$ ). Also, residual matter results more dispersed across the surface of passive elements (mean SDE area $11.9 \mathrm{~cm}^{2}$ ) than active ones (mean area $3.1 \mathrm{~cm}^{2}$ ). In terms of residue sampling, our results indicate that passive tools have more potentials for the retrieval of use-related residues.

As already pointed out in our previous work (Zupancich et al. 2019), the spatial distribution of residues across the surface can provide important hints concerning sampling strategies (Fig. 11). In the case of passive elements utilized in resting percussion activities, residues are dispersed across the used surface of the tool, generally far from the immediate proximity of the utilized portion. This confirms what previously observed for starch granules (Zupancich et al. 2019) allowing us to assume that, also in the case of GSTs used to process animal tissues through resting percussion, the outer parts of the utilized area of the tool are best suited for sampling. Conversely, in the case of passive tools employed in thrusting percussion, most of the residual matter remains clustered, suggesting residues should be sampled over the utilized area of the surface preferably. In the case of active tools, there is no particular difference in the disposition of residues according to the gestures or worked materials. In all the cases, residues are concentrated within the utilized area of the tools, indicating this latter as the more promising sampling spot.

Overall, we expect that the results discussed in this paper will allow us to obtain high-resolution functional reconstructions of the Mesolithic GSTs from the Danube Gorges for at least four reasons. First, by better defining functional attributes of active and passive tools in GST assemblages, our dataset provides ground for understanding in which capacity GSTs participated in the chaine opératoire of osseous artefacts and in plant food processing in the Danube Gorges, something so far hypothesized only through the analysis of other strands of archaeological evidence. Second, given the capacity of PSR to identify extremely processed collagen fibres in our experimental record, we expect such staining method to become key for consolidating the functional interpretations of archaeological tools involved in animal processing, often based on the qualitative assessment of use wear only. Third, through the association of specific use wear with patterns of residue distribution on our experimental tools we have provided a solid ground for reducing the risk of 

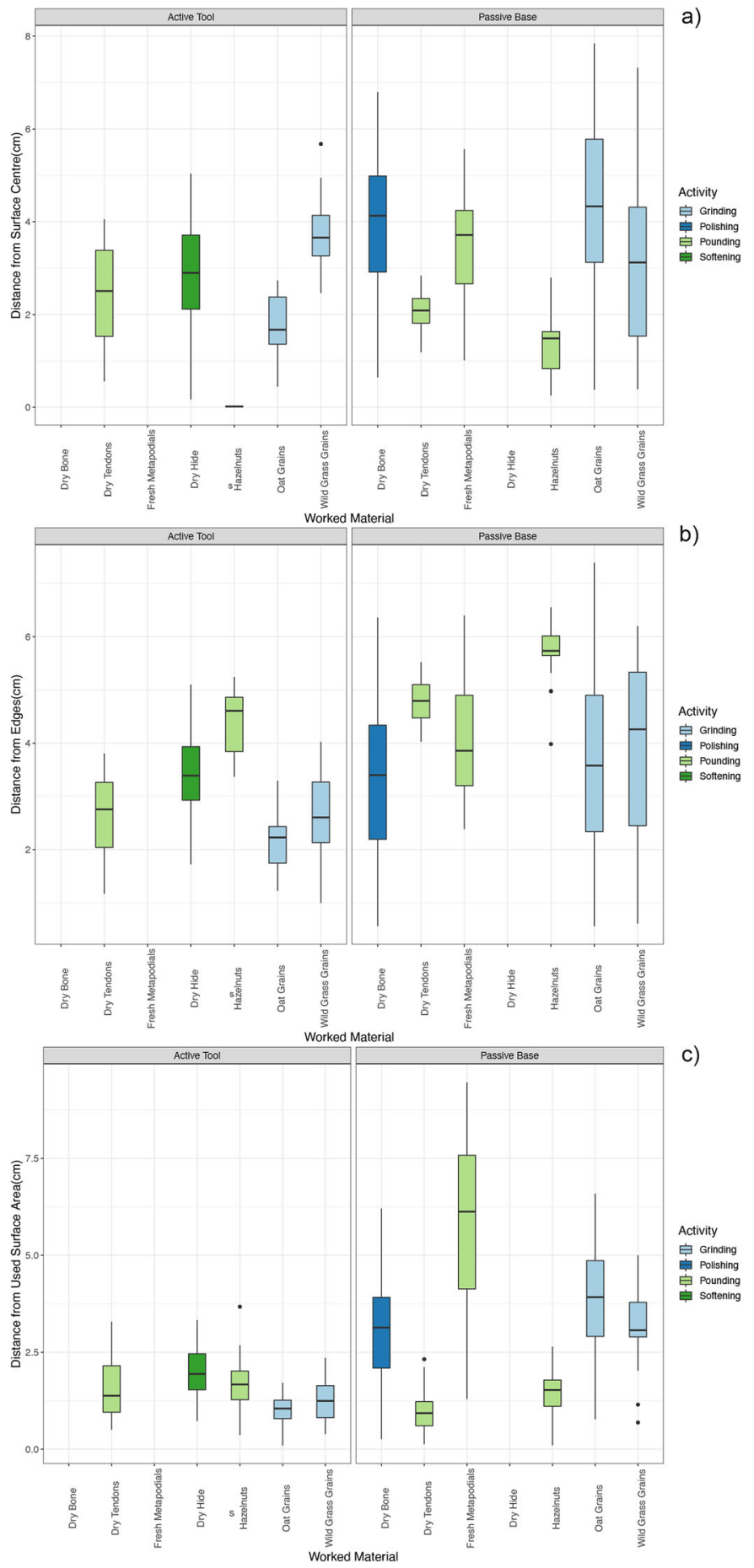

Fig. 11 Boxplots of the a distance of the residue from the geometric centre of the surface, $\mathbf{b}$ distance of the residues from the surface edges and $\mathbf{c}$ distance of the residues from the geometric centre of the utilized area of the surface 
modern contamination (e.g. non-authentic ancient use-related residues) in the functional interpretation of Mesolithic GSTs. Last, by highlighting preferential areas for sampling intact starch granules on both active and passive tools, our results provide experimental ground for comparing plant structures retrieved in dental calculus and those recovered from GSTs displaying plant-related use wear traces.

\section{Conclusions}

GSTs are generally characterized by long life cycles and represent a valuable means for studying technological behaviours, cultural traditions, subsistence practices and socio-economic changes in ancient prehistoric human groups. In this paper, we tested a multi stranded approach involving the qualitative and quantitative assessment of use wear traces and residues and the analysis of the patterns of residue spatial distribution for disentangling such intrinsic complexity and reconstructing the functions of prehistoric GSTs.

Specific surface modifications associated with different uses of sandstone GSTs were identified and described at low and high magnifications, using both reflected and transmitted light. Overall, our data show no differences in macro and micro use wear features between active and passive GSTs, except for the GST used for nut cracking. In this case, a clear depression developed over the surface of the passive tool.

Morphological characteristics of residues were also recognized, and we highlighted how the use of biochemical staining can improve the interpretation of animal tissues. Also, the advantages of applying a GIS analysis to the analysis of residues were identified in the possibility to detect specific patterns of distribution across the GSTs and relate them to the gesture performed, the worked materials and the surface topography. Overall, our results suggest that the spatial distribution of residues depends on the gesture performed and the type of surface modification produced rather than on the kind of material processed during the activity (i.e. animal or vegetal). Also, active tools seem to be less likely to entrap use-related residues than passive elements, and the latter ones should be preferred (when possible) for residue sampling. Such results have the potential to advance archaeological residue sampling strategies, hence reducing the risk of misinterpreting residues due to ancient or modern contamination. Last, we stressed the potential of a combined use wear and residue analysis, carried out directly in situ through reflected optical microscopy and in the laboratory using biochemical staining and cross-polarized transmitted light observations, for the analysis of tools used for processing animal matters.

Considering the positive results obtained on sandstone GSTs, we believe that the future implementation of the methodology presented in this paper through the design of new experimental frameworks will assess its potential also in the analysis of tools made of other raw materials.

Acknowledgements The authors are also grateful to Dr. Dušan Borić for helping out with raw material acquisition and to Dr. Maria Letizia Carra for her precious contribution for processing plants for this research. We are also grateful to Dr. Rossella Duches, Dr. Elisabetta Flor, Dr. Alex Fontana and Dr. Nicola Nannini for 
providing access to the facilities of the MUSE (Museum of Science of Trento) and collaborating in the experimental activity. The authors would also like to express their huge gratitude to Dr. Birgitta Stephenson for her insights on biochemical staining. We want to express our gratitude to the four reviewers for their careful reading of and their constructive feedback to our manuscript. The comments we received were key to ameliorate the manuscript.

Authors' Contributions E.C. and A.Z. conceived the study, gathered, analysed and discussed experimental data. E.C. performed residues analysis; A.Z. performed use wear and the spatial distribution of the residues. Both the authors wrote and revised the manuscript.

Funding Open access funding provided by Università degli Studi di Roma La Sapienza within the CRUICARE Agreement. We acknowledge the funding received for this project through the European Research Council (ERC Starting Grant Project HIDDEN FOODS, G.A. no. 639286 to E.C.).

\section{Compliance with Ethical Standards}

Conflict of Interest The authors declare that they have no conflict of interest.

Open Access This article is licensed under a Creative Commons Attribution 4.0 International License, which permits use, sharing, adaptation, distribution and reproduction in any medium or format, as long as you give appropriate credit to the original author(s) and the source, provide a link to the Creative Commons licence, and indicate if changes were made. The images or other third party material in this article are included in the article's Creative Commons licence, unless indicated otherwise in a credit line to the material. If material is not included in the article's Creative Commons licence and your intended use is not permitted by statutory regulation or exceeds the permitted use, you will need to obtain permission directly from the copyright holder. To view a copy of this licence, visit http://creativecommons.org/licenses/by/4.0/.

\section{References}

Adams, J. L. (1999). Refocusing the role of food-grinding tools as correlates for subsistence strategies in the U.S. southwest. American Antiquity, 64(3), 475-498.

Adams, J. L. (2014). Ground stone use-wear analysis: a review of terminology and experimental methods. Journal of Archaeological Science, 48, 129-138.

Adams, J. L., Delgado, S., Dubreuil, L., Hamon, C., Plisson, H., \& Risch, R. (2006). Functional analysis of macro-lithic artefacts: a focus on working surfaces. In I. F. Sternke, L. Eigeland, \& L.-J. Costa (Eds.), Presented at the Non-Flint Raw Material Use in Prehistory. Archaeopress.

Antonović, D., Perić, S., \& Resimić-Šarić, K. (2006). Stone Tools from Lepenski Vir. Institute of Archaeology.

Aranguren, B., Becattini, R., Lippi, M. M., \& Revedin, A. (2007). Grinding flour in Upper Palaeolithic Europe (25 000 years bp). ANTIQUITY-OXFORD, 81(314), 845-855.

Arroyo, A., \& de la Torre, I. (2018). Pounding tools in HWK EE and EF-HR (Olduvai Gorge, Tanzania): percussive activities in the Oldowan-Acheulean transition. Journal of HumanEevolution, 120, 402-421.

Arroyo, A., \& de la Torre, I. (2020). Pitted stones in the Acheulean from Olduvai Gorge beds III and IV (Tanzania): a use-wear and 3D approach. Journal of Human Evolution, 145, 102837.

Arroyo, A., Hirata, S., Matsuzawa, T., \& De La Torre, I. (2016). Nut cracking tools used by captive chimpanzees (pan troglodytes) and their comparison with early stone age percussive artefacts from Olduvai Gorge. PLoS One, 11(11), e0166788. https://doi.org/10.1371/journal.pone.0166788.

Arroyo, A., Harmand, S., Roche, H., \& Taylor, N. (2020). Searching for hidden activities: percussive tools from the Oldowan and Acheulean of West Turkana, Kenya (2.3-1.76 ma). Journal of Archaeological Science, 123, 105238.

Banks, W. E., \& Kay, M. (2003). High resolution casts for lithic use-wear analysis. Lithic Technology, 28(1), 27-34.

Barton, H., Mutri, G., Hill, E., Farr, L., \& Barker, G. (2018). Use of grass seed resources c.31 ka by modern humans at the Haua Fteah cave, Northeast Libya. Journal of Archaeological Science, 99, 99-111. 
Belfer-Cohen, A., \& Hovers, E. (2005). The ground stone assemblages of the Natufian and Neolithic societies in the Levant - a brief review (pp. 299-308). Mitekufat Haeven: Journal of the Israel Prehistoric Society.

Benito-Calvo, A., Carvalho, S., Arroyo, A., Matsuzawa, T., \& de la Torre, I. (2015). First GIS analysis of modern stone tools used by wild chimpanzees (Pan troglodytes verus) in Bossou, Guinea, West Africa. PLoS One, 10(3), e0121613.

Benito-Calvo, A., Arroyo, A., Sánchez-Romero, L., Pante, M., \& de la Torre, I. (2018). Quantifying 3D micro-surface changes on experimental stones used to break bones and their implications for the analysis of early stone age pounding tools. Archaeometry, 60(3), 419-436.

Borić, D. (2001). Mesolithic and early Neolithic hunters and fishers in the Danube Gorges: an analysis of archaeozoological data. Archaeolingua.

Borić, D. (2002). Seasons, life cycles and memory in the Danube gorges, c. 10000-5500 BC Cal. Unpublished $\mathrm{PhD}$ dissertation: University of Cambridge, UK.

Borić, D., French, C. A. I., Stefanović, S., Dimitrijević, V., Cristiani, E., Gurova, M., Antonović, D., Allué, E., \& Filipović, D. (2014). Late Mesolithic lifeways and deathways at Vlasac (Serbia). Journal of Field Archaeology, 39(1), 4-31.

Borić, D., Higham, T., Cristiani, E., Dimitrijević, V., Nehlich, O., Griffiths, S., Alexander, C., Mihailović, B., Filipović, D., Allué, E., \& Buckley, M. (2018). High-resolution AMS dating of architecture, boulder artworks and the transition to farming at Lepenski Vir. Scientific Reports, 8(1), 14221.

Bril, B., Smaers, J., Steele, J., Rein, R., Nonaka, T., Dietrich, G., Biryukova, E., Hirata, S., \& Roux, V. (2012). Functional mastery of percussive technology in nut-cracking and stone-flaking actions: experimental comparison and implications for the evolution of the human brain. Philosophical transactions of the Royal Society of London. Series B, Biological sciences, 367(1585), 59-74.

Brufau, G., Boatella, J., \& Rafecas, M. (2006). Nuts: source of energy and macronutrients. The British Journal of Nutrition, 96(Suppl 2), S24-S28.

Caricola, I., Zupancich, A., Moscone, D., Mutri, G., Falcucci, A., Duches, R., et al. (2018). An integrated method for understanding the function of macro-lithic tools. Use wear, 3D and spatial analyses of an Early Upper Palaeolithic assemblage from North Eastern Italy. PLoS One, 1-46.

Caruana, M. V., Carvalho, S., Braun, D. R., Presnyakova, D., Haslam, M., Archer, W., et al. (2014). Quantifying traces of tool use: a novel morphometric analysis of damage patterns on percussive tools. PLoS One, 9(11), 1-18.

Carvalho, S., Beardmore-Herd, M., Carvalho, S., \& Beardmore-Herd, M. (2019). Technological origins: primate perspectives and early hominin tool use in Africa. Oxford Research Encyclopedia of African History, (March), 1-27.

Cnuts, D., \& Rots, V. (2018). Extracting residues from stone tools for optical analysis: towards an experimentbased protocol. Archaeological and Anthropological Sciences, 10(7), 1717-1736.

Cristiani, E., \& Borić, D. (2012). 8500-year-old Late Mesolithic garment embroidery from Vlasac (Serbia): Technological, use-wear and residue analyses. Journal of Archaeological Science, 39(11), 3450-3469.

Cristiani, E., \& Borić, D. (2020). Technology of osseous artefacts in the Mesolithic Danube Gorges: The evidence from Vlasac (Serbia). In: D. Borić, D. Antonović, B. Mihailović (Eds.) Mesolithic Assemblages. Vol.2. Papers Presented at the Ninth International Conference on the Mesolithic in Europe, Belgrade 2015

Cristiani, E., Živaljević, I., \& Borić, D. (2014). Residue analysis and ornament suspension techniques in prehistory: cyprinid pharyngeal teeth beads from Late Mesolithic burials at Vlasac (Serbia). Journal of Archaeological Science, 46, 292-310.

Cristiani, E., Radini, A., Edinborough, M., \& Borić, D. (2016). Dental calculus reveals Mesolithic foragers in the Balkans consumed domesticated plant foods. Proceedings of the National Academy of Sciences, 113(37), 10298-10303.

Cristiani, E., Radini, A., Borić, D., Robson, H. K., Caricola, I., Carra, M., Mutri, G., Oxilia, G., Zupancich, A., Šlaus, M., \& Vujević, D. (2018). Dental calculus and isotopes provide direct evidence of fish and plant consumption in Mesolithic Mediterranean. Scientific Reports, 8(1), 8147.

de Beaune, S. A. (2004). The invention of technology: prehistory and cognition. Current Anthropology, 45(2), $139-162$.

de la Torre, I., Benito-Calvo, A., Arroyo, A., Zupancich, A., \& Proffitt, T. (2013). Experimental protocols for the study of battered stone anvils from Olduvai Gorge (Tanzania). Journal of Archaeological Science, 40(1), 313-332.

Delgado-Raack, S., \& Risch, R. (2008). Towards a systematic analysis of grain processing technologies. Methodological Improvements and Archaeological Inference: Recent Functional Studies on Non Flint Stones Tools. 
Delgado-Raack, S., Gómez-Gras, D., \& Risch, R. (2009). The mechanical properties of macrolithic artifacts: a methodological background for functional analysis. Journal of Archaeological Science, 36(9), 18231831.

Dietrich, L., \& Haibt, M. (2020). Bread and porridge at Early Neolithic Göbekli Tepe: a new method to recognize products of cereal processing using quantitative functional analyses on grinding stones. Journal of Archaeological Science: Reports, 33, 102525.

Dietrich, L., Meister, J., Dietrich, O., Notroff, J., Kiep, J., Heeb, J., Beuger, A., \& Schütt, B. (2019). Cereal processing at Early Neolithic Göbekli Tepe, southeastern Turkey. PLoS One, 14(5), e215214.

Dubreuil, L., \& Nadel, D. (2015). The development of plant food processing in the Levant: insights from usewear analysis of Early Epipalaeolithic ground stone tools. Philosophical Transactions of the Royal Society of London. Series B, Biological Sciences, 370(1682). https://doi.org/10.1098/rstb.2014.0357.

Dubreuil, L., \& Plisson, H. (2010). Natufian flint versus ground stone tools: a use-wear perspective on subsistence change. Eurasian Prehistory, 7(1), 45-60.

Dubreuil, L., \& Savage, D. (2014). Ground stones: a synthesis of the use-wear approach. Journal of Archaeological Science, 48, 139-153.

Dubreuil, L., Savage, D., Delgado-Raack, S., Plisson, H., Stephenson, B., \& de la Torre, I. (2015). Current analytical frameworks for studies of use-wear on ground stone tools. In J. M. Marreiros, J. F. Gibaja Bao, \& N. Ferreira Bicho (Eds.), Use-wear and residue analysis in archaeology (pp. 105-158). Cham: Springer International Publishing.

Dubreuil, L., Ovadia, A., Shahack-Gross, R., \& Grosman, L. (2019). Evidence of ritual breakage of a ground stone tool at the Late Natufian site of Hilazon Tachtit cave (12,000 years ago). PLoS One, 14(10), e0223370.

Evershed, R. P., Heron, C., Charters, S., \& Goad, L. J. (1991). The survival of food residues: new methods of analysis, interpretation and application. Proceedings of the British Academy, 77(February 1991), 187208.

Fullagar, R., Hayes, E., Stephenson, B., Field, J., Matheson, S., \& Fitzsimmons, K. (2015). Evidence for Pleistocene seed grinding at Lake Mungo, south-eastern Australia. Archaeology in Oceania, 50, 3-19.

Fullagar, R., Stephenson, B., \& Hayes, E. (2017). Grinding grounds: Function and distribution of grinding stones from an open site in the Pilbara, western Australia. Quaternary International, 427, 175-183.

Hamon, C. (2008). Functional analysis of stone grinding and polishing tools from the earliest Neolithic of north-western Europe. Journal of Archaeological Science, 35(6), 1502-1520.

Hamon, C., \& Plisson, H. (2009). Functional analysis of grinding stones: the blind-test contribution. In L. L. Skakun N. (Ed.), Prehistoric Technology 40 years later: Functional Studies and the Russian Legacy (pp. 29-38) BAR International Series.

Haslam, M. (2004). The decomposition of starch grains in soils: implications for archaeological residue analyses. Journal of Archaeological Science, 31(12), 1715-1734.

Haslam, M., Hernandez-Aguilar, A., Ling, V., Carvalho, S., De La Torre, I., Destefano, A., et al. (2009). Primate archaeology. Nature, 460(7253), 339-344.

Haslam, M., Gumert, M. D., Biro, D., Carvalho, S., \& Malaivijitnond, S. (2013). Use-wear patterns on wild macaque stone tools reveal their behavioural history. PLoS One, 8(8), 1-8.

Hayes, E., \& Rots, V. (2019). Documenting scarce and fragmented residues on stone tools: an experimental approach using optical microscopy and SEM-EDS. Archaeological and Anthropological Sciences, 11(7), 3065-3099.

Hayes, E., Cnuts, D., Lepers, C., \& Rots, V. (2017). Learning from blind tests: determining the function of experimental grinding stones through use-wear and residue analysis. Journal of Archaeological Science: Reports, 11, 245-260.

Hayes, E., Pardoe, C., \& Fullagar, R. (2018). Sandstone grinding/pounding tools: use-trace reference libraries and Australian archaeological applications. Journal of Archaeological Science: Reports, 20, 97-114.

Henry, A. G. (2020). Starch granules as markers of diet and behavior. In A. G. Henry (Ed.), Handbook for the analysis of micro-particles in archaeological samples (pp. 97-116). Cham: Springer International Publishing.

Horrocks, M. (2005). A combined procedure for recovering phytoliths and starch residues from soils, sedimentary deposits and similar materials. Journal of Archaeological Science, 32(8), 1169-1175.

Ibáñez, J.J., González-Urquijo, J.E., Gibaja, J. (2014). Discriminating wild vs domestic cereal harvesting micropolish through laser confocal microscopy. Journal of Archaeological Science, 48, 96-103.

Ibáñez, J. J., Lazuen, T., González-Urquijo, J. (2019). Identifying experimental tool use through confocal microscopy. Journal of Archaeological Method and Theory, 26(3), 1176-1215.

Langejans, G. H. J. (2011). Discerning use-related micro-residues on tools: testing the multi-stranded approach for archaeological studies. Journal of Archaeological Science, 38(5), 985-1000. 
Li, W., Tsoraki, C., Lan, W., Yang, Y., Zhang, J., \& van Gijn, A. (2019). New insights into the grinding tools used by the earliest farmers in the central plain of China. Quaternary International, 529, 10-17.

Li, W., Tsoraki, C., Yang, Y., Xin, Y., \& van Gijn, A. (2020). Plant foods and different uses of grinding tools at the Neolithic site of Tanghu in Central China. Lithic Technology, 1-11.

Lippi, M. M., Foggi, B., Aranguren, B., Ronchitelli, A., \& Revedin, A. (2015). Multistep food plant processing at Grotta Paglicci (Southern Italy) around 32,600 cal BP. Proceedings of the National Academy of Sciences, 112(39), 12075-12080.

Liu, L., Wang, J., \& Levin, M. J. (2017). Usewear and residue analyses of experimental harvesting stone tools for archaeological research. Journal of Archaeological Science: Reports, 14, 439-453.

Lucarini, G., \& Radini, A. (2019). First direct evidence of wild plant grinding process from the Holocene Sahara: use-wear and plant micro-residue analysis on ground stone tools from the Farafra oasis. Quaternary International: Egypt https://www.sciencedirect.com/science/article/pii/S1040618219303258.

Lucarini, G., Radini, A., Barton, H., \& Barker, G. (2016). The exploitation of wild plants in Neolithic North Africa. Use-wear and residue analysis on non-knapped stone tools from the Haua Fteah cave, Cyrenaica, Libya. Quaternary International, 410, 77-92.

Macdonald, D. A., Harman, R., \& Evans, A. A. (2018). Replicating surface texture: preliminary testing of molding compound accuracy for surface measurements. Journal of Archaeological Science: Reports, 18(February), 839-846.

Marinova, E., Filipovic, D., Obradović, D., \& Allué, E. (2013). Wild plant resources and land use in the Mesolithic and early Neolithic south-east Europe: archaeobotanical evidence from the Danube catchment of Bulgaria and Serbia. Offa, 69, 467-478.

Marreiros, J., Calandra, I., Gneisinger, W., Paixão, E., Pedergnana, A., \& Schunk, L. (2020). Rethinking usewear analysis and experimentation as applied to the study of past Hominin tool use. Journal of Paleolithic Archaeology., 3(3), 475-502. https://doi.org/10.1007/s41982-020-00058-1.

Mercader, J., Abtosway, M., Baquedano, E., Bird, R. W., Díez-Martín, F., Domínguez-Rodrigo, M., Favreau, J., Itambu, M., Lee, P., Mabulla, A., Patalano, R., Pérez-González, A., Santonja, M., Tucker, L., \& Walde, D. (2017). Starch contamination landscapes in field archaeology: Olduvai Gorge, Tanzania. Boreas, 46(4), 918-934.

Mercader, J., Akeju, T., Brown, M., Bundala, M., Collins, M. J., Copeland, L., Crowther, A., Dunfield, P., Henry, A., Inwood, J., Itambu, M., Kim, J. J., Larter, S., Longo, L., Oldenburg, T., Patalano, R., Sammynaiken, R., Soto, M., Tyler, R., \& Xhauflair, H. (2018). Exaggerated expectations in ancient starch research and the need for new taphonomic and authenticity criteria. Facets, 3(1), 777-798.

Pardoe, C., Fullagar, R., \& Hayes, E. (2019). Quandong stones: a specialised Australian nut-cracking tool. PLoS One, 14(10), e0222680.

Pedergnana, A., \& Ollé, A. (2016). Monitoring and interpreting the use-wear formation processes on quartzite flakes through sequential experiments. Quaternary International, 427, 35-65.

Piperno, D. R., Ranere, A. J., Holst, I., \& Hansell, P. (2000). Starch grains reveal early root crop horticulture in the Panamanian tropical forest. Nature, 407(6806), 894-897.

Piperno, D. R., Weiss, E., Holst, I., \& Nadel, D. (2004). Processing of wild cereal grains in the Upper Palaeolithic revealed by starch grain analysis. Nature, 430(7000), 670-673.

Procopiou, H., Anderson, P., Formenti, F., \& Juan-Tresseras, J. (2002). Étude des matiéres transformées sur les outils de mouture: identification des residus et des traces d'usure par analyse chimique et par observations en microscopie optique et electronique. Moudre et Broyer. L'interprétation fonctionnelle de l'outillage de mouture et de broyage dans la préhistoire et l'Antiquité. I-Méthodes, pétrographie, chimie, tracéologie, expérimentation, ethnoarchéologie, 11-128.

Proffitt, T., Luncz, V. L., Malaivijitnond, S., Gumert, M., Svensson, M. S., \& Haslam, M. (2018). Analysis of wild macaque stone tools used to crack oil palm nuts. Royal Society Open Science, 5(3), 171904. https:// doi.org/10.1098/rsos. 171904 .

Revedin, A., Aranguren, B., Becattini, R., Longo, L., Marconi, E., Lippi, M. M., Skakun, N., Sinitsyn, A., Spiridonova, E., \& Svoboda, J. (2010). Thirty thousand-year-old evidence of plant food processing. Proceedings of the National Academy of Sciences of the United States of America, 107(44), 1881518819.

Rosenberg, D. (2008). The possible use of acorns in past economies of the Southern Levant: a staple food or a negligible food source? Levantina, 40(2), 167-175.

Rots, V. (2010). Prehension and hafting traces on flint tools: a methodology (p. 273). Leuven: Leuven University Press.

Srejović, D. (1969). The roots of the Lepenski Vir culture. Archaeologia Iugoslavica, 10, 13-21.

Srejović, D. (1972). New discoveries at Lepenski Vir. Thames \& Hudson (London).

Srejović, D., \& Babovic, L. (2011). Lepenski vir. National museum of Belgrade. 
Stephenson, B. (2015). A modified Picro-Sirius Red (PSR) staining procedure with polarization microscopy for identifying collagen in archaeological residues. Journal of Archaeological Science, 61, 235-243.

Stoddard, F. L. (1999). Survey of starch particle-size distribution in wheat and related species. Cereal Chemistry, 76(1), 145-149.

Stroulia, A. (2003). Ground stone Celts from Franchthi cave: a close look. Hesperia: The Journal of the American School of Classical Studies at Athens, 72(1), 1-30.

Tringham, R., Cooper, G., Odell, G. H., Voytek, B., \& Whitman, A. (1974). Experimentation in the formation of edge damage: a new approach to lithic analysis. Journal of Field Archaeology, 1, 171-196.

van Gijn, A. (2010). Flint in focus; lithic biographies in the Neolithic and bronze age. Leiden: Sidestone Press.

Wadley, L., \& Lombard, M. (2007). Small things in perspective: the contribution of our blind tests to microresidue studies on archaeological stone tools. Journal of Archaeological Science, 34(6), 1001-1010.

Wright, K. I. (karen). (2014). Domestication and inequality? Households, corporate groups and food processing tools at Neolithic Çatalhöyük. Journal of Anthropological Archaeology, 33, 1-33.

Xhauflair, H., Pawlik, A., Forestier, H., Saos, T., Dizon, E., \& Gaillard, C. (2017). Use-related or contamination? Residue and use-wear mapping on stone tools used for experimental processing of plants from Southeast Asia. Quaternary International, 427, 80-93.

Yang, X., \& Perry, L. (2013). Identification of ancient starch grains from the tribe Triticeae in the North China Plain. Journal of Archaeological Science, 40(8), 3170-3177.

Zupancich, A., \& Cristiani, E. (2020). Functional analysis of sandstone macro-ground stone tools: Arguments for a qualitative and quantitative synergetic approach. Scientific Reports, 10(1), 15740. https://doi.org/10. 1038/s41598-020-72276-0.

Zupancich, A., Mutri, G., Caricola, I., Carra, M. L., Radini, A., \& Cristiani, E. (2019). The application of 3D modeling and spatial analysis in the study of groundstones used in wild plants processing. Archaeological and Anthropological Sciences, 11(9), 4801-4827. https://doi.org/10.1007/s12520-019-00824-5.

Publisher's Note Springer Nature remains neutral with regard to jurisdictional claims in published maps and institutional affiliations.

\section{Affiliations}

\section{E. Cristiani ${ }^{1} \cdot$ A. Zupancich $^{1}$}

1 DANTE-Diet and Ancient Technology Laboratory, Department of Oral and Maxillo Facial Sciences, Sapienza University of Rome, Via Caserta 6, 00161 Rome, Italy 